\title{
1 Mechanical competition alters the cellular interpretation of an endogenous genetic
} programme

Sourabh Bhide ${ }^{1,2}$, Denisa Gombalova ${ }^{1,2, \#, ~ G r e g o r ~ M o ̈ n k e ~}{ }^{1, \#}$, Johannes Stegmaier ${ }^{3}$, Valentyna

6 Zinchenko ${ }^{2,4}$, Anna Kreshuk ${ }^{4}$, Julio M Belmonte ${ }^{5,6}$, Maria Leptin ${ }^{1,7^{*}}$

${ }^{1}$ Director's Research Unit, European Molecular Biology Laboratory, Heidelberg, Germany

$9{ }^{2}$ Collaboration for joint PhD degree between EMBL and Heidelberg University, Faculty of

10 Biosciences, Heidelberg, Germany

$11{ }^{3}$ Institute of Imaging and Computer Vision, RWTH Aachen University, Aachen, Germany

$12{ }^{4}$ Cell Biology and Biophysics Unit, European Molecular Biology Laboratory, Heidelberg, Germany

$13{ }^{5}$ Department of Physics, North Carolina State University, USA

$14{ }^{6}$ Quantitative and Computational Developmental Biology Cluster, North Carolina State University, 15 USA

$16{ }^{7}$ European Molecular Biology Organization, Heidelberg, Germany

17

18

19

\#These authors contributed equally

* Corresponding author

Drosophila gastrulation, epithelial folding, contractility, cytoskeleton, morphogenesis, actomyosin 24 pulses, tissue mechanics 


\section{Abstract}

26 The intrinsic genetic programme of a cell is not sufficient to explain all of the cell's activities. External

27 mechanical stimuli are increasingly recognized as determinants of cell behaviour. In the epithelial

28 folding event that constitutes the beginning of gastrulation in Drosophila, the genetic programme of

29 the future mesoderm leads to the establishment of a contractile actomyosin network that triggers

30 apical constriction of cells, and thereby, tissue folding. However, some cells do not constrict but

31 instead stretch, even though they share the same genetic programme as their constricting

32 neighbours. We show here that tissue-wide interactions force these cells to expand even when an

33 otherwise sufficient amount of apical, active actomyosin is present. Models based on contractile

34 forces and linear stress-strain responses do not reproduce experimental observations, but

35 simulations in which cells behave as ductile materials with non-linear mechanical properties do. Our

36 models show that this behaviour is a general emergent property of actomyosin networks [in a

37 supracellular context, in accordance with our experimental observations of actin reorganisation

38 within stretching cells. 


\section{Introduction}

40 Epithelial tissues are shaped during animal development by changes in the geometry, number or relative positions of their constituent cells. Cells change their shape by actively generating intracellular forces or by passively responding to external forces, from within the organism, such as neighbouring cells, or by forces from outside the body ${ }^{1-4}$. The actomyosin meshwork underlying the plasma membrane is the major source of morphogenetic forces ${ }^{5-7}$ which can be transmitted over larger, supracellular distances via cell junctions. The functioning of the cytoskeleton itself can be influenced by external mechanical forces ${ }^{8}$. In some systems, we are beginning to understand how forces act on a tissue scale ${ }^{9}$, but we know much less about the interplay of active forces and passive deformation and their genetic and molecular basis. Understanding the actomyosin contraction patterns in the individual cells that make up a tissue is unlikely to be sufficient to explain all the force changes and deformations within the entire tissue.

One example of epithelial morphogenesis is the formation of the ventral furrow during Drosophila gastrulation, an epithelial folding event that internalizes the future mesoderm, driven by active forces generated in an autonomous manner in the central part of the mesoderm ${ }^{10}$. Many studies have focused on these cells and their contractile actomyosin meshwork. We understand the major mechanisms that act within each cell: the proteins that are specifically activated in these cells change the location of the adherens junctions and recruit an active actomyosin meshwork to the apical cell cortex, which undergoes a series of pulsatile contractions until the apical surface is fully constricted ${ }^{11-14}$.

To allow the furrow to internalize the mesoderm without causing disruptions elsewhere in the embryo, other parts of the embryonic epithelium obviously must respond or contribute to the movement. The cells outside the mesoderm appear not to contribute actively to furrow formation ${ }^{15}$, but their compliance is later required for the furrow to invaginate fully ${ }^{16}$. The most important cells that enable the furrow to form are the mesodermal cells adjacent to the initial indentation. While central cells constrict, lateral cells expand their apical surfaces ${ }^{16,17}$.

In spite of their distinct behaviours, the constricting and expanding cells of the mesoderm share the same developmental program. They express the same genes, albeit with quantitative differences, but no known genes are absolutely restricted to one or other population ${ }^{18,19}$. There is a graded expression of important gene products from the centre to the edges of the mesoderm (Fig. $1 \mathrm{~A}$ ), in particular for the genes necessary for myosin activation ( $f \circ g, t 48$ and mist) and junction remodelling (traf4) which are deployed under the control of the dorsal-ventral patterning system ${ }^{20-}$ ${ }^{27}$. While their quantitative differences have prompted the question whether the two populations should be considered distinct 'subdomains', each relevant gene has a different expression boundary, so they together cannot be seen as defining a genetic domain ${ }^{27}$.

Current models for cell shape determination in the ventral furrow ${ }^{28-32}$ assume that changes in apical surface area correlate with the force generated by contractile actomyosin. In the first phase of invagination, the degree of apical constriction mirrors the graded distribution of apical myosin, with absence of myosin having been correlated with lack of constriction of lateral cells ${ }^{16,33,34}$.

It is not clear by what mechanism the quantitative differences in gene expression can cause dramatic qualitative differences in cell behaviour: any two immediately adjacent cells in the mesoderm primordium have similar gene expression profiles. Thus, in the absence of any known genetic correlations for the pronounced differences, there must be other explanations for how these 
bioRxiv preprint doi: https://doi.org/10.1101/2020.10.15.333963; this version posted December 1, 2020. The copyright holder for this preprint (which was not certified by peer review) is the author/funder, who has granted bioRxiv a license to display the preprint in perpetuity. It is made available under aCC-BY-NC-ND 4.0 International license.

82 behaviours arise. Specifically, we need explanations for how the smooth and graded differences in 83 expression levels of effector molecules is converted into a step difference in cell behaviour.

84 We compare here in a quantitative manner the cellular activities in the mesoderm, contrast them 85 with existing models, and propose and test a new model that explains qualitative differences in cell 86 behaviour. Our results suggest that two distinct cell behaviours emerge not from strict differences in 87 genetic control, but from tissue-wide mechanical interactions. 


\section{Results}

\section{Cell shape evolution across mesoderm and neighbouring populations}

Analyses of shape changes in the prospective mesoderm (hereafter simply called 'mesoderm') often focus on the 10-cell-wide central band of cells that form the initial furrow. The lateral cells are less well studied, partly because the forces for folding are generated in central cells, but also because their rapid displacement and extreme shape changes make them difficult to image ${ }^{35}$. We extracted faithful two-dimensional views of the apical surface of the entire mesoderm (surface 'peels' ${ }^{36}$ Suppl. Fig. $1 \mathrm{~A}-\mathrm{C}$ ) for quantitative analysis. The breadth of the mesoderm varies along the AP axis and between embryos; we therefore define the cell rows operationally from row 1 at the midline to row 8 as the outer row adjacent to the mesectoderm; Suppl. Fig. 1).

Furrow formation starts with cells in rows 1 - 6 constricting in a stepwise and stochastic manner ${ }^{12,37}$. The last cells to constrict are those in row 6 , while rows 7 and 8 expand their surfaces anisotropically ${ }^{21-23,33,35}$, stretching towards the midline. Mesectodermal cells also stretch slightly, but beyond them the ectoderm remains inert. Thus, mesodermal cells can either constrict or stretch, with initially indistinguishable neighbours in rows 6 and 7 taking on dramatically different developmental paths. In addition, rows 7 and 8 do not respond equally to the force from the centre. Row 7 expands first and most strongly, followed by row 8 and finally the mesectoderm (Fig. 1C-D).

Theoretical models and simulations based on bell-shaped contractility gradients create epithelial shape changes with highly constricted cells in the centre and cell sizes increasing in a graded manner with distance from the centre ${ }^{16,31-33,38}$. Inverted patterns of stretching have so far been obtained in computational models only for cells without contractility ${ }^{31,39,40}$. To investigate this inconsistency, we examined actomyosin in lateral cells.

\section{Actomyosin gradient as a predictor for cell shape behaviour}

F-actin is present in two distinct but interacting pools with different morphological functions in the early embryonic epithelium: a fine meshwork underlying the apical cortex, and a large pool associated with apical junctions and baso-lateral cell membranes ${ }^{12,31,41-45}$. Junctional actin is reduced in the mesoderm in unison with the relocation of adherens junctions before shape changes begin ${ }^{44,46,47}$ (Suppl. Fig. 2). The apical meshwork changes along the entire dorso-ventral axis around the time of gastrulation but remains present during furrow formation as a fibrous network both in central and lateral mesodermal cells ${ }^{16}$ (Suppl. Fig. 2I-K).

We focused our further analyses on myosin, on which the contractile forces in the mesoderm depend. The amount of myosin regulatory chain (encoded by the gene sqh in Drosophila) within the apical cortex has been used as a proxy for the contractile actomyosin meshwork ${ }^{12,48-51}$. When the central cells begin to constrict, practically no apical myosin is seen in the lateral cells ${ }^{33}$ (Fig. 1D-E). Levels rise over the next few minutes, reaching values seen in central cells at earlier points, when the cells constrict. For example, the level in row 7 at $525 \mathrm{sec}$ resembles that in rows 3 and 4 at 325 sec. We also calculated the concentrations, and still find that row 7 at $525 \mathrm{sec}$ reaches similar concentrations as rows 3 to 5 at $275 \mathrm{sec}$ (Fig. 2F). Thus, apical myosin levels alone are not sufficient to explain why lateral cells do not constrict.

Another possibility is that in spite of having sufficient myosin, lateral cells cannot assemble a functional contractile meshwork. Epithelial apical actomyosin meshworks normally show a strong dynamic behaviour characterised by fluctuations or 'pulses' of myosin foci that correlate with periods of apical constriction ${ }^{12,48,52}$. We see myosin foci forming, moving and disappearing in lateral 
132 cells in a similar manner as in central cells (Fig. 2G). Myosin pulses in lateral cells have been

133 characterised as less persistent ${ }^{47}$, but they are nevertheless able to pull on nearby plasma

134 membrane, thereby narrowing the cell (Suppl. Fig. 3), indicating an active, force-generating

135 actomyosin meshwork. Thus, in this regard lateral cells are not qualitatively different from central

136 cells.

\section{Visco-elastic model of the mesoderm}

139 Taking into account the myosin levels in lateral cells, we explored in a computational model whether

140 a simple contractility gradient could explain the bifurcation into constriction and expansion, the

141 inverted pattern of stretching and the apical size ratios. With a mathematical description of our

142 myosin measurements per cell row, we modelled the mesoderm and mesectoderm as a line of 19

143 visco-elastic "cells" with a given stress-strain response, bordered by three stiffer 'ectodermal' cells

144 on each side. Each "cell" changes size based on the forces acting on its boundaries, which in turn

145 depend on the difference of the myosin levels in the cells on either side of the boundary (Suppl Fig.

146 4). The simulation showed constriction in central cells and stretching in lateral cells, but not with the

147 pattern of size ratios observed in the embryo. This might be explained by inaccuracies in our myosin

148 measurements, but systematically varying the width and steepness of the myosin profile also did not

149 yield outputs corresponding to the in vivo data, nor did changes in the slope of the stress-strain

150 curves.

151 We therefore tested whether the assumption of a linear stress-strain response in the cells was 152 wrong, as also seems to be the case in other instances ${ }^{8,53,66,67}$. We considered four classes of non153 linear stress-strain responses: superelastic (like nickel-titanium alloys) with strain-softening beyond

154 the proportional limit followed by strain-hardening while remaining elastic; elastoplastic (like

155 aluminium), with a similar stress-strain relationship but permanent deformation (yielding);

156 elastomeric (like rubber or silicon), with a decrease in stiffness after the proportional limit, but no

157 strain-softening; and a stiffening model (like biopolymer networks), with increased stiffness after the 158 proportional limit (Suppl Fig. 5B). Unlike the linear models, non-linear models with strain-softening 159 (superelastic- and elastoplastic) reproduced the stretching pattern of lateral cells for a wide range of 160 myosin profiles (Fig. 2, Suppl Fig. 5). While inert materials and cultured cells can respond to strain by 161 stiffening ${ }^{64-67}$, simulations with strain-stiffening curves did not reproduce our in vivo observations.

162 These results led us to re-examine the actomyosin meshwork in lateral cells since a strain-softening 163 would most likely manifest as permanent or reversible reorganisations of the cytoskeletal network.

\section{Organisation of actomyosin networks in lateral cells}

166 We had noticed that local constrictions in lateral cells occurred primarily in the AP axis (Suppl Fig. 5), pointing to a possible role for overall actomyosin distribution. We analysed the distribution of

168 apical myosin and found preferential segregation towards the ventral side in each cell (Fig. 2F).

169 While the asymmetry is visible in all cell rows, there are larger areas without myosin and the 170 distance of displacement is greater in lateral cells (Fig. 2G-J). This uneven distribution may reflect the strain-softening or yielding behaviour predicted necessary by the model. This resembles the asymmetric distribution of Rho in expanded central cells in concertina mutants, which has been 173 proposed as an explanation for the cells' inability to overcome the expansile forces acting on them and constrict ${ }^{54}$. The reason for the asymmetry may be the myosin gradient. For every cell along the gradient the ventral neighbour constricts earlier than its dorsal neighbour. Recent simulations

176 showed that the ability of the cell cortex to yield to contractile forces feeds back on the orientation 
177 of the contractile network, which becomes depleted near 'softer' and enriched near 'stiffer'

178 membranes ${ }^{55}$. In mesodermal cells, the least yielding should be the ventral side, which experiences

179 stronger forces from the ventral neighbour than the other side does from the dorsal neighbour. If

180 the extent to which a cell at any moment expands or shrinks is influenced by its neighbours, then the

181 differential concentration of myosin within the cell and its surrounding should correlate with the

182 cell's size changes. We therefore compared these parameters and did indeed find such a correlation

183 ( $\sim 75$; Fig. $2 \mathrm{~K}$ insert). The overall the concentration of myosin within a cell, unsurprisingly,

184 correlated highly with the concentration in its neighbours. Cells with high concentrations always

185 constricted, and all cells remained inert at low concentrations. But in the range between these

186 values, for any given cell-internal myosin concentration, the cells that expanded were always those

187 for which the neighbours had the highest myosin levels (Fig. 2L, K insert). This shows that forces

188 acting on each cell from its neighbours have an important role in determining the cell's behaviour.

\section{Actomyosin model of the mesoderm}

We do not know whether the correlation between actomyosin distribution and cell stretching reflects causality, or whether both are effects of external forces, i.e. pulling by neighbours. We used a microscopic, filament-based mode $\left.\right|^{56,57}$ to test under what conditions cells containing contractile actomyosin show the behaviours we observe in the embryo. We again used a chain of "membrane"separated elements with fixed outer boundaries (Fig 2M). Each "cell" contained a constant number of actin filaments and crosslinkers, and membranes had attachment points for filaments. We varied the number of active myosin motors according to the same distributions as in the visco-elastic model.

A set of profiles was able to generate constriction of 6 and stretching of 3 cells, of which a subset reproduced the qualitative behaviour seen in vivo, with an inverted pattern of stretching (red region in Fig. 2Q). For such profiles, 'cell 7 ' stretches until its actomyosin network tears apart, disconnecting the more lateral cells from the constricting cells (Fig. $2 \mathrm{~N}^{-N^{\prime}}$ ). In conclusion, without a priori assumptions, this model gives an output consistent with our experimental observations and indicative of non-linear (yielding) behaviour, showing that such behaviour can emerge directly from the properties of the network components and the myosin concentrations. The striking similarity between the parameters of the myosin profiles in the two unrelated models (microscopic and viscoelastic) that yield the same results (though with an offset of 1 cell-width; Fig. 2Q,R) illustrates the generality of the results and suggests that contractile meshworks in vivo can, in theory, do the same. Rapid cell expansion due to strain-softening has also been observed in elegant tissue culture experiments, where persistent intermediate filaments allowed re-establishment of connectivity and the cell re-contracting ${ }^{8}$. Our results here are the first demonstration of an equivalent process occurring in a physiological situation in vivo.

\section{Intrinsic versus externally imposed behaviours of mesodermal cells}

215 Our results so far show that cell-intrinsic genetic regulation or myosin levels alone cannot explain

216 the difference between constricting and stretching. We also compared the role of myosin levels

217 among cells at the same position in the gradient. Many central cells expand transiently before

218 constricting and some are internalized without constricting ${ }^{58}$; Suppl. Fig. 6). We tested whether

219 myosin levels correlated with these behaviours by categorising cells from all rows as either

220 'transiently expanding' or 'contracting'. In rows $3-5$, transiently expanding cells started out with

221 slightly larger surfaces, but the same myosin concentrations as contracting cells. During the transient 
expansion (150-250 seconds) neither myosin amounts nor concentration are pronouncedly different from the contracting cells (175 sec; Suppl. Fig. 6). Myosin amounts in row 6 (Suppl. Fig. 6F-J) also rose simultaneously in both populations during the expansion period, the slight divergence in concentration therefore coinciding but not preceding expansion. Thus, myosin levels did not predict constriction versus transient expansion. Finally, central cells that remain unconstricted often have highly asymmetric myosin foci (Fig. 2G-H), much like lateral expanding cells, showing that skewed myosin is not determined by the cell's position in the genetic gradient, nor by its myosin values. Instead, it seems that myosin distribution in stretching cells is a consequence rather than a cause of their apical size. Together these results suggest that whether a cell constricts does not depend primarily on myosin levels, but at least in part on what its neighbours do, and in part by stochastic variation in its actomyosin organization.

We therefore propose a model where all mesodermal cells have the capacity to constrict in principle, but cells that accumulate active actomyosin earlier or at higher levels than neighbouring cells have a greater chance of sustaining their contraction. This hypothesis makes two testable predictions: (a) preventing central cells from constricting early should allow lateral cells to constrict, and (b), making lateral cells constrict early should affect the ability of central cells to constrict.

To test these predictions, we manipulated apical contractility by laser ablation and optogenetic methods. We first inhibited constriction in central cells by laser-mediated severing of the actomyosin meshwork (Fig. 3). This strongly reduced apical constriction in the illuminated area, and some cells in rows 7 and 8 now constricted their apical sides (Fig. 3D-D", 3G, Suppl. video 4). Optogenetically inactivating the actomyosin meshwork ${ }^{59}$ yielded the same results: constriction in the illuminated cells was inhibited, several cells in rows 7 and 8 constricted (Fig. $\left.3 \mathrm{H}-\mathrm{K}^{\prime \prime}\right)$. Thus, when central cells are prevented from constricting, lateral cells are able to constrict.

To test whether the central cells can be stretched, we optogenetically induced premature constriction in lateral cells ${ }^{10}$. We activated regions either side of the central two rows but only in the posterior half of the embryo, retaining the anterior half as control. In the control half, central cells constricted and a gradient of apical areas developed (Fig. $4 A^{\prime}-D^{\prime}$ ). In the experimental half, ectopic apical constriction occurred in the illuminated cells. At the same time, many of the cells near the ventral midline now expanded their apical surfaces (Fig. 4A'"-D'). Thus, central cells failed to undergo their normal morphogenetic programme, even though they themselves had not been manipulated, showing that external forces were able to override their genetic instruction to constrict. 


\section{Discussion}

Following from the above, an explanation is needed why lateral cells normally do not constrict, even though they reach sufficient myosin levels. The simplest explanation is that the external forces acting on them are greater than those acting on the early-constricting central cells. While different external forces are likely part of the explanation, in the absence of precise measurements at a subcellular level (an extremely challenging task given the cells' small size and rapid movement) we must also consider other possibilities.

According to our visco-elastic model, a non-linear stress-strain relation is necessary for the inverted pattern of stretching of lateral cells, which could not be reproduced with previous computational models. The strong stretching, also documented in epithelia in vitro ${ }^{8}$, was best recapitulated by a superelastic response. The non-linearity emerging from the microscopic model, however, resembles elastoplasticity (irreversible strain), but the simulations do not include actin turnover which would facilitate recovery from yielding of the cytoskeletal network and thus reverse the stretching, typical of superelastic materials. It is currently not feasible to determine experimentally whether cells in the embryo behave like elastoplastic or superelastic materials (as seen in vitro ${ }^{8}$ and simple organisms ${ }^{53}$ ). Other possible explanations for the same output include dissipation through viscosity ${ }^{38,63}$ or external friction ${ }^{3,4}$, or a non-proportional causal relationship between myosin concentration and constriction forces. The former cannot explain single cell stretching in the central mesoderm, while the latter is unlikely given that myosin levels alone predict a wide range of morphogenetic movements in Drosophila ${ }^{51}$

A source of this non-linearity may be the actomyosin not assembling in the proper structure. The pulsatile apico-medial actin meshwork needs to be tightly connected to the junctional complexes to function ${ }^{13,14,42,60,61}$ relying also on an underlying non-pulsatile actin meshwork ${ }^{62}$. Despite the homogeneous actin meshwork in stretching cells, the areas that are free of active myosin occupy a large proportion of the apical surface - similar to ectodermal or amnioserosa cells in which the connection of pulsatile foci to the underlying actin meshwork is lost ${ }^{62}$. The observation that a skewed myosin distribution is not restricted to cells with low myosin but can occur even in central cells at the highest myosin concentrations underscores the conclusion that all aspects of this phenotype are externally imposed rather than intrinsically determined by myosin levels.

Dilution of cortical myosin may compromise the cell's ability to make sufficient physical connections, in particular along the dorso-ventral axis, so that even if sufficient force is generated, it cannot shorten the cell in the long dimension. In other words, even though the cells have enough myosin to create force, the system is not properly engaged and its force is not transmitted to the cell boundary. In this model, the skewed myosin distribution is both a result of external forces and also part of the cause of a cells' failure to constrict. By a feed-forward mechanism, an initial expansion induced by constricting neighbours dilutes or distorts the apical actomyosin, giving these cells a lower chance of generating or sustaining a contraction. This mechanism, which we propose corresponds to the non-linear behaviour predicted by the models, would apply both to central and to lateral cells, with a catastrophic 'flip' being stochastic and rare in central cells, but reproducible in lateral cells because of the temporal and spatial gradient in which contractions occur. 


\section{Acknowledgments}

296 We thank Mayank Kumar and Catarina Carmo for help with generating fly lines; Dimitri Kromm and

297 Lars Hufnagel for expert help for MuVi SPIM imaging; Marvin Albert for support on image

298 registration; Stefano De Renzis, Hernan Garcia, Thomas Lecuit for stocks and reagents; the EMBL

299 Advanced Light Microscopy Facility (ALMF) for continuous support; Alexandre Cunha and Thiago

300 Vallin-Spina for providing access to SEGMENT3D; Steffen Lemke, Karen Daniels, Justin Crocker,

301 Stefano de Renzis, Aissam Ikmi, Xavier Trepat, Pavel Tomancak and the Leptin lab for critical

302 comments and discussions. This work was supported by funding from EMBO and DFG grant

303 FOR1756.

305 Author Contributions

306 Conceptualization, S.B., M.L.; Methodology and investigation, S.B., J.S., D.G., G.M. V.Z. ; Formal

307 Analysis, S.B., D.G., G.M., V.Z.; Writing - Original Draft, S.B., J.M.B, M.L.; Writing - Review \& Editing,

308 S.B., M.L.; Visualization, S.B., J.S., D.G., V.Z.; Simulations, J.M.B, G.M.; Supervision, A.K, J. M. B.; M.L.;

309 Funding Acquisition, M.L. 


\section{References}

1 Halbleib, J. M. \& Nelson, W. J. Cadherins in development: cell adhesion, sorting, and tissue morphogenesis. Genes Dev 20, 3199-3214, doi:10.1101/gad.1486806 (2006).

2 Leerberg, J. M. et al. Tension-sensitive actin assembly supports contractility at the epithelial zonula adherens. Curr Biol 24, 1689-1699, doi:10.1016/j.cub.2014.06.028 (2014). Bailles, A. et al. Genetic induction and mechanochemical propagation of a morphogenetic wave. Nature 572, 467-473, doi:10.1038/s41586-019-1492-9 (2019). Munster, S. et al. Attachment of the blastoderm to the vitelline envelope affects gastrulation of insects. Nature 568, 395-399, doi:10.1038/s41586-019-1044-3 (2019). Lecuit, T. \& Lenne, P. F. Cell surface mechanics and the control of cell shape, tissue patterns and morphogenesis. Nat Rev Mol Cell Biol 8, 633-644, doi:10.1038/nrm2222 (2007).

6 Roper, K. Supracellular actomyosin assemblies during development. Bioarchitecture 3, 45-49, doi:10.4161/bioa.25339 (2013). Salbreux, G., Charras, G. \& Paluch, E. Actin cortex mechanics and cellular morphogenesis. Trends Cell Biol 22, 536-545, doi:10.1016/j.tcb.2012.07.001 (2012).

8 Latorre, E. et al. Active superelasticity in three-dimensional epithelia of controlled shape. Nature 563, 203-208, doi:10.1038/s41586-018-0671-4 (2018). Shyer, A. E. et al. Villification: how the gut gets its villi. Science 342, 212-218, doi:10.1126/science.1238842 (2013).

10 Izquierdo, E., Quinkler, T. \& De Renzis, S. Guided morphogenesis through optogenetic activation of Rho signalling during early Drosophila embryogenesis. Nat Commun 9, 2366, doi:10.1038/s41467-018-04754-z (2018).

11 Dawes-Hoang, R. E. et al. folded gastrulation, cell shape change and the control of myosin localization. Development 132, 4165-4178, doi:10.1242/dev.01938 (2005).

12 Martin, A. C., Kaschube, M. \& Wieschaus, E. F. Pulsed contractions of an actin-myosin network drive apical constriction. Nature 457, 495-499, doi:10.1038/nature07522 (2009).

13 Martin, A. C., Gelbart, M., Fernandez-Gonzalez, R., Kaschube, M. \& Wieschaus, E. F. Integration of contractile forces during tissue invagination. J Cell Biol 188, 735-749, doi:10.1083/jcb.200910099 (2010).

341

14 Kanesaki, T., Hirose, S., Grosshans, J. \& Fuse, N. Heterotrimeric G protein signaling governs the cortical stability during apical constriction in Drosophila gastrulation. Mech Dev 130, 132-142, doi:10.1016/j.mod.2012.10.001 (2013). Leptin, M. \& Roth, S. Autonomy and non-autonomy in Drosophila mesoderm determination and morphogenesis. Development (1994).

1 Rauzi, M. et al. Embryo-scale tissue mechanics during Drosophila gastrulation movements. Nat Commun 6, 8677, doi:10.1038/ncomms9677 (2015).

17 Oda, H. \& Tsukita, S. Real-time imaging of cell-cell adherens junctions reveals that Drosophila mesoderm invagination begins with two phases of apical constriction of cells. $J$ Cell Sci 114, 493-501 (2001).

18 Karaiskos, N. et al. The Drosophila embryo at single-cell transcriptome resolution. Science 358, 194-199, doi:10.1126/science.aan3235 (2017).

19 Sandmann, T. et al. A core transcriptional network for early mesoderm development in Drosophila melanogaster. Genes Dev 21, 436-449, doi:10.1101/gad.1509007 (2007).

20 Turner, F. R. \& Mahowald, A. P. Scanning electron microscopy of Drosophila melanogaster embryogenesis. II. Gastrulation and segmentation. Dev Biol 57, 403-416 (1977).

21 Leptin, M. \& Grunewald, B. Cell shape changes during gastrulation in Drosophila. Development (1990). ventral furrow and posterior midgut invaginations. (1991). 
bioRxiv preprint doi: https://doi.org/10.1101/2020.10.15.333963; this version posted December 1, 2020. The copyright holder for this preprint (which was not certified by peer review) is the author/funder, who has granted bioRxiv a license to display the preprint in perpetuity. It is made available under aCC-BY-NC-ND 4.0 International license.

36123 Parks, S. \& Wieschaus, E. The Drosophila gastrulation gene concertina encodes a G alpha-like protein. Cell 64, 447-458 (1991).

363 Costa, M., Wilson, E. T. \& Wieschaus, E. A putative cell signal encoded by the folded gastrulation gene coordinates cell shape changes during Drosophila gastrulation. Cell 76, 1075-1089 (1994). gastrulation by apical localization of adherens junctions and RhoGEF2. Science 315, 384-386, doi:10.1126/science.1134833 (2007).

26 Mathew, S. J., Rembold, M. \& Leptin, M. Role for Traf4 in polarizing adherens junctions as a prerequisite for efficient cell shape changes. Mol Cell Biol 31, 4978-4993, doi:10.1128/MCB.05542-11 (2011).

27 Lim, B., Levine, M. \& Yamazaki, Y. Transcriptional Pre-patterning of Drosophila Gastrulation. Curr Biol 27, 286-290, doi:10.1016/j.cub.2016.11.047 (2017).

28 Conte, V., Munoz, J. J. \& Miodownik, M. A 3D finite element model of ventral furrow invagination in the Drosophila melanogaster embryo. J Mech Behav Biomed Mater 1, 188198, doi:10.1016/j.jmbbm.2007.10.002 (2008).

29 Conte, V., Munoz, J. J., Baum, B. \& Miodownik, M. Robust mechanisms of ventral furrow invagination require the combination of cellular shape changes. Phys Biol 6, 016010, doi:10.1088/1478-3975/6/1/016010 (2009).

30 Hocevar, B. A., Rauzi, M., Leptin, M. \& Ziherl, P. A model of epithelial invagination driven by collective mechanics of identical cells. Biophys J 103, 1069-1077, doi:10.1016/j.bpj.2012.07.018 (2012).

31 Spahn, P. \& Reuter, R. A Vertex Model of Drosophila Ventral Furrow Formation. PLoS ONE 8, e75051, doi:10.1371/journal.pone.0075051 (2013).

32 Polyakov, O. et al. Passive mechanical forces control cell-shape change during Drosophila ventral furrow formation. Biophys J 107, 998-1010, doi:10.1016/j.bpj.2014.07.013 (2014).

33 Heer, N. C. et al. Actomyosin-based tissue folding requires a multicellular myosin gradient. Development 144, 1876-1886, doi:10.1242/dev.146761 (2017).

34 Perez-Mockus, G. et al. Spatial regulation of contractility by Neuralized and Bearded during furrow invagination in Drosophila. Nat Commun 8, 1594, doi:10.1038/s41467-017-01482-8 (2017).

35 Fuse, N., Yu, F. \& Hirose, S. Gprk2 adjusts Fog signaling to organize cell movements in Drosophila gastrulation. Development 140, 4246-4255, doi:10.1242/dev.093625 (2013).

36 Bhide, S., Mikut, R., Leptin, M. \& Stegmaier, J. Semi-Automatic Generation of Tight Binary Masks and Non-Convex Isosurfaces for Quantitative Analysis of 3D Biological Samples.(IEEE ICIP 2020) <https://ui.adsabs.harvard.edu/abs/2020arXiv200111469B >.

37 Kam, Z., Minden, J. S., Agard, D. A., Sedat, J. W. \& Leptin, M. Drosophila gastrulation: analysis of cell shape changes in living embryos by three-dimensional fluorescence microscopy. Development 112, 365-370 (1991).

38 Doubrovinski, K., Swan, M., Polyakov, O. \& Wieschaus, E. F. Measurement of cortical elasticity in Drosophila melanogaster embryos using ferrofluids. Proc Natl Acad Sci U S A 114, 1051-1056, doi:10.1073/pnas.1616659114 (2017).

39 Odell, G. M., Oster, G., Alberch, P. \& Burnside, B. The mechanical basis of morphogenesis. I. Epithelial folding and invagination. Dev Biol 85, 446-462 (1981).

40 Pouille, P. A. \& Farge, E. Hydrodynamic simulation of multicellular embryo invagination. Phys Biol 5, 015005, doi:10.1088/1478-3975/5/1/015005 (2008).

41 Morize, P., Audrey, E. C. C., Mike. \& Parks, P. a. E. W. Hyperactivation of the folded gastrulation pathway induces specific cell shape changes. Development (1998). cell constriction in Drosophila. Development 134, 567-578, doi:10.1242/dev.02748 (2007). 
411

412

413

414

415

416

417

418

419

420

421

422

423

424

425

426

427

428

429

430

431

432

433

434

435

436

437

438

439

440

441

442

443

444

445

446

447

448

449

450

451

452

453

454

455

456

457

458

459

460

461
43 Sawyer, J. K., Harris, N. J., Slep, K. C., Gaul, U. \& Peifer, M. The Drosophila afadin homologue Canoe regulates linkage of the actin cytoskeleton to adherens junctions during apical constriction. J Cell Biol 186, 57-73, doi:10.1083/jcb.200904001 (2009).

44 Mason, F. M., Tworoger, M. \& Martin, A. C. Apical domain polarization localizes actin-myosin activity to drive ratchet-like apical constriction. Nat Cell Biol 15, 926-936, doi:10.1038/ncb2796 (2013).

45 Jodoin, J. N. et al. Stable Force Balance between Epithelial Cells Arises from F-Actin Turnover. Dev Cell 35, 685-697, doi:10.1016/j.devcel.2015.11.018 (2015).

46 Mason, F. M., Xie, S., Vasquez, C. G., Tworoger, M. \& Martin, A. C. RhoA GTPase inhibition organizes contraction during epithelial morphogenesis. J Cell Biol 214, 603-617, doi:10.1083/jcb.201603077 (2016).

47 Denk-Lobnig, M., Heer, N. C. \& Martin, A. Combinatorial patterns of graded RhoA activation and uniform F-actin depletion promote tissue curvature. bioRxiv doi: https://doi.org/I0.II0I/2020.04.I5.043893 (2020).

48 Rauzi, M., Lenne, P. F. \& Lecuit, T. Planar polarized actomyosin contractile flows control epithelial junction remodelling. Nature 468, 1110-1114, doi:10.1038/nature09566 (2010).

49 Vasquez, C. G., Tworoger, M. \& Martin, A. C. Dynamic myosin phosphorylation regulates contractile pulses and tissue integrity during epithelial morphogenesis. J Cell Biol 206, 435450, doi:10.1083/jcb.201402004 (2014).

50 Kerridge, S. et al. Modular activation of Rho1 by GPCR signalling imparts polarized myosin II activation during morphogenesis. Nat Cell Biol 18, 261-270, doi:10.1038/ncb3302 (2016).

51 Streichan, S. J., Lefebvre, M. F., Noll, N., Wieschaus, E. F. \& Shraiman, B. I. Global morphogenetic flow is accurately predicted by the spatial distribution of myosin motors. Elife 7, doi:10.7554/eLife.27454 (2018).

52 Blanchard, G. B., Murugesu, S., Adams, R. J., Martinez-Arias, A. \& Gorfinkiel, N. Cytoskeletal dynamics and supracellular organisation of cell shape fluctuations during dorsal closure. Development 137, 2743-2752, doi:10.1242/dev.045872 (2010).

53 Jia, F., Ben Amar, M., Billoud, B. \& Charrier, B. Morphoelasticity in the development of brown alga Ectocarpus siliculosus: from cell rounding to branching. J $R$ Soc Interface 14, doi:10.1098/rsif.2016.0596 (2017).

54 Xie Shicong, F. M. M., and Adam C. Martin. Loss of Ga12/13 exacerbates apical area dependence of actomyosin contractility. Molecular Biology of Cell, doi:10.1091/mbc.E16-050305) (2016).

55 Chanet, S. et al. Actomyosin meshwork mechanosensing enables tissue shape to orient cell force. Nat Commun 8, 15014, doi:10.1038/ncomms15014 (2017).

56 Belmonte, J. M., Leptin, M. \& Nedelec, F. A theory that predicts behaviors of disordered cytoskeletal networks. Mol Syst Biol 13, 941, doi:10.15252/msb.20177796 (2017).

57 Nedelec, F. \& Foethke, D. Collective Langevin Dynamics of Flexible Cytoskeletal Fibers. (2009). <arXiv:0903.5178>.

58 Yevick, H. G., Miller, P. W., Dunkel, J. \& Martin, A. C. Structural Redundancy in Supracellular Actomyosin Networks Enables Robust Tissue Folding. Dev Cell 50, 586-598 e583, doi:10.1016/j.devcel.2019.06.015 (2019).

59 Guglielmi, G., Barry, J. D., Huber, W. \& De Renzis, S. An Optogenetic Method to Modulate Cell Contractility during Tissue Morphogenesis. Dev Cell 35, 646-660, doi:10.1016/j.devcel.2015.10.020 (2015).

60 Spahn, P., Ott, A. \& Reuter, R. The PDZ-GEF protein Dizzy regulates the establishment of adherens junctions required for ventral furrow formation in Drosophila. J Cell Sci 125, 38013812, doi:10.1242/jcs.101196 (2012).

61 Krueger, D., Pallares Cartes, C., Makaske, T. \& De Renzis, S. betaH-spectrin is required for ratcheting apical pulsatile constrictions during tissue invagination. EMBO Rep, e49858, doi:10.15252/embr.201949858 (2020). 
46262 Dehapiot, B. et al. Assembly of a persistent apical actin network by the formin Frl/Fmnl

463 tunes epithelial cell deformability. Nat Cell Biol, doi:10.1038/s41556-020-0524-x (2020). D'Angelo, A., Dierkes, K., Carolis, C., Salbreux, G. \& Solon, J. Probing tissue-scale deformation by in vivo force application reveals a fast tissue softening during early embryogenesis.

466

467 doi:10.1101/167155 (2017).

468

64 Gardel, M. L. et al. Elastic behavior of cross-linked and bundled actin networks. Science 304, 1301-1305, doi:10.1126/science.1095087 (2004).

470

65 Storm, C., Pastore, J. J., MacKintosh, F. C., Lubensky, T. C. \& Janmey, P. A. Nonlinear elasticity in biological gels. Nature 435, 191-194, doi:10.1038/nature03521 (2005).

66 Fernandez, P., Pullarkat, P. A. \& Ott, A. A master relation defines the nonlinear viscoelasticity of single fibroblasts. Biophys J 90, 3796-3805, doi:10.1529/biophysj.105.072215 (2006).

67 Hoffman, B. D., Massiera, G., Van Citters, K. M. \& Crocker, J. C. The consensus mechanics of cultured mammalian cells. Proc Natl Acad Sci U S A 103, 10259-10264, doi:10.1073/pnas.0510348103 (2006). microscope for rapid in toto imaging. Nat Methods 9, 730-733, doi:10.1038/nmeth.2064 (2012). Viswanathan, R. et al. Optogenetic inhibition of Delta reveals digital Notch signalling output during tissue differentiation. EMBO Rep 20, e47999, doi:10.15252/embr.201947999 (2019). Bothma, J. P. et al. Enhancer additivity and non-additivity are determined by enhancer strength in the Drosophila embryo. Elife 4, doi:10.7554/eLife.07956 (2015).

483

484 Schindelin, J. et al. Fiji: an open-source platform for biological-image analysis. Nat Methods 9, 676-682, doi:10.1038/nmeth.2019 (2012).

486

487

72 Aigouy, B., Umetsu, D. \& Eaton, S. Segmentation and Quantitative Analysis of Epithelial
Tissues. Methods Mol Biol 1478, 227-239, doi:10.1007/978-1-4939-6371-3 13 (2016).

73 Pauli Virtanen, Ralf Gommers, Travis E. Oliphant et al. SciPy 1.0: Fundamental Algorithms for Scientific Computing in Python. Nature Methods, 17(3), 261-272. (2020).

74 Johannes Stegmaier et al. Cell Segmenation in 3D Confocal images using Supervoxel MergeForests with CNN-based Hypothesis selection. arXiv (2017).

75 Royou, A., Field, C., Sisson, J. C., Sullivan, W. \& Karess, R. Reassessing the role and dynamics of nonmuscle myosin II during furrow formation in early Drosophila embryos. Mol Biol Cell 15, 838-850, doi:10.1091/mbc.e03-06-0440 (2004).

76 Bothma, J. P., Norstad, M. R., Alamos, S. \& Garcia, H. G. LlamaTags: A Versatile Tool to Image Transcription Factor Dynamics in Live Embryos. Cell 173, 1810-1822 e1816, doi:10.1016/j.cell.2018.03.069 (2018).

77 Garcia, H. G., Tikhonov, M., Lin, A. \& Gregor, T. Quantitative imaging of transcription in living Drosophila embryos links polymerase activity to patterning. Curr Biol 23, 2140-2145, doi:10.1016/j.cub.2013.08.054 (2013).

78 John D. Hunter. Matplotlib: A 2D Graphics Environment, Computing in Science \& Engineering, 9, 90-95, DOI:10.1109/MCSE.2007.55 (2007)

79 Wes McKinney. Data Structures for Statistical Computing in Python, Proceedings of the 9th Python in Science Conference, 51-56 (2010)

80 Stéfan van der Walt, Johannes L. Schönberger, et al. scikit-image: Image processing in Python, PeerJ 2:e453 (2014)

81 Charles R. Harris, K. Jarrod Millman, Stéfan J. van der Walt, et al. Array programming with NumPy, Nature, 585, 357-362, DOI:10.1038/s41586-020-2649-2 (2020) 


\section{Supplementary information}

510

511

512

513

514

515

516

517

518

519

520

521

522

523

524

525

526

527

528

529

530

531

532

533

534

535

536

537

538

539

540

541

542

543

544

545

546

547

548

549

550

551

552

\section{Plasmid for membrane-associated mCardinalisepi}

To generate the plasmid attb-tubulin_promoter-GAP43::mCardinal-K10 plasmid, the attb-UASp-K10 plasmid (provided by Anne Ephrussi, EMBL Heidelberg) was modified by replacing the UAS promoter by a tubulin promoter sequence that was amplified from the plasmid pCasper4-tubulin (provided by Stefano De Renzis, EMBL Heidelberg). The mCardinal coding sequence was amplified from mCardinal-H2B-C-10 (Addgene plasmid \#56162) using a forward primer with the sequence encoding the first 20 amino acids of the GAP43 protein from Bos taurus (Table S6). The GAP43::mCardinal fragment was inserted into the attb-tubulin-promoter-K10 plasmid using Notl and BamH enzymes.

\section{Generation of fly stocks}

To generate the fly transgenic lines $p$ [mat tub>GAP43::mCardinal]/Cyo and $p$ [mat tub> GAP43::mCardinal]/TM6 Tb, the attb-tubulin_promoter-GAP43::mCardinal-K10 plasmid was inserted into landing sites on the second and third chromosomes (landing sites VK18 (\#BDSC-9736) and VK33(\#BDSC-9750)) by BestGene Inc. (California, USA). Only the insertion on the second chromosome was used in this study because it was brighter than the insertion in VK33.

\section{Sample preparation}

Embryos were collected according to standard procedures on apple juice agar plates. Plates were changed after a one-hour embryo collection and kept at $25^{\circ} \mathrm{C}$ for 2.5 hours. Individual mid-to-late cellularization embryos were hand-selected under halocarbon 27 oil. The stage-selected embryos were devitellinised with $50 \%$ bleach and washed thoroughly with distilled water. For confocal microscopy, the embryos were then mounted on a glass-bottom microwell dish with the ventral or ventral-lateral side facing the glass and covered with PBS. For MuVi-SPIM the embryos were mounted in $1 \%$ Gelrite inside a glass capillary and multiple views registered and fused ${ }^{16}$.

\section{Confocal microscopy}

For visualising 3D cell shapes using 2-photon illumination, a femtosecond-pulsed infrared laser (Chameleon Compact OPO Family, Coherent) tuned at $950 \mathrm{~nm}$ emission wavelength and coupled with Zeiss LSM 780 confocal microscope was used. The region of interest was defined with the Zen 'Regions' interface and the embryos were illuminated with 20-25\% laser power. A volume of $200 \mathrm{x}$ $500 \times 60 \mu \mathrm{m}^{3}$ was imaged, where the dimension of $200 \mu \mathrm{m}$ is along the anterior-posterior axis of the embryo, centred around the central region, $500 \mu \mathrm{m}$ is along the left-right axis, and $60 \mu \mathrm{m}$ is depth in the $z$ axis.

Two-colour imaging was performed at room temperature with a Zeiss 880 Airyscan microscope, a 40X/1.4 numerical aperture oil-immersion objective, an argon ion laser and a 561-nm diode laser. Image stacks were acquired every $25 \mathrm{sec}$.

\section{Selective plane illumination microscopy}

Imaging was performed on a custom-built Multi-View SPIM set-up ${ }^{68}$ with Nikon 10/0.3W objective lenses for illumination and Nikon 20/1.0W objective lenses for detection. An additional 1.5X magnification tube lens produced an effective image pixel size of $0.19 \mu \mathrm{m} \times 0.19 \mu \mathrm{m}$. Optical sections were recorded with a typical spacing of $0.75-1 \mu \mathrm{m}$. For observing cell shape changes, 
GAP43::mCardinal embryos were imaged from two opposing directions simultaneously and successively from two directions with 90 degree apart. Registration of the four views was performed as previously described ${ }^{16}$.

556

\section{Identification of mesodermal cells}

558 To identify unambiguously the lateral borders of the mesoderm we used two methods (Suppl Fig.

559 1D-J'): i) back-tracing mesectodermal cells from the point when the meet at the ventral midline after

560 the mesoderm is fully internalised; or ii) using the MS2 stem loop/MCP-GFP system to visualize the expression of the genes singleminded ${ }^{69}$ in mesectodermal cells or snail in the mesoderm ${ }^{70}$.

562

563

\section{Laser ablation and illumination}

564 Laser-based actomyosin meshwork ablation was performed as previously described ${ }^{16}$ using a femtosecond-pulsed infrared laser (Chameleon Compact OPO Family, Coherent) tuned at $950 \mathrm{~nm}$ emission wavelength and coupled to an LSM Zeiss 780 confocal microscope. The Zen 'Bleaching' interface was used to create the region of interest and was illuminated at $65-70 \%$ laser power. For this experiment, C-Apochromat 63X magnification water immersion Zeiss Objective with 1.1 NA was used (infrared corrected).

\section{Optogenetic manipulations}

572 Embryos were prepared in a room where the blue spectrum of visible light was filtered out ${ }^{10}$. The

573 Zen 'Regions' interface was used to create the region of interest and the embryos were illuminated

574 with 15-20\% laser power with pixel dwell time between 0.8 and $1.27 \mathrm{~ms}$. For this experiment, a C-

575 Apochromat 40X magnification water immersion Zeiss Objective with 1.2 NA was used (infrared 576 corrected) and an infrared laser (Chameleon Compact OPO Family, Coherent) tuned to $950 \mathrm{~nm}$ emission were used.

\section{Apical surface extraction from SPIM images}

582 The $30 \%$ of central part the embryos along the anterior-posterior axis was cropped in $\mathrm{Fiji}^{11}$. A custom MATLAB software was then used to extract the apical surfaces ${ }^{36}$. A binary mask around the embryo was generated semi-automatically by defining the apical and basal surfaces. Using these masks, distance transformation was used to define a 1 to 2-pixel 'peel' typically 2-3 pixels below the binary mask. Along the anterior-posterior axis of the embryo, pixels along the surface were traced and mapped onto a line. This process was performed on every stack to map the apical surface of the embryo onto a 2D plane.

\section{Myosin measurements}

591 Images were deconvolved in the ZEN software using AiryProcessing. The Spider:GFP images

592 represent confocal slices $3 \mu \mathrm{m}$ below the apical cortex. Sqh:Cherry images represent sum Z-

593 projections of an apical section of the same depth upon background myosin subtraction. Background 594 myosin intensity was measured in single subapical confocal slices, mean +2 standard deviations 595 were subtracted from each slice before Z-projecting to obtain apical myosin intensity. The cells were 596 segmented and tracked using TissueAnalyzer ${ }^{72}$. The segmentation output was used to extract cell 
597 areas and pixel intensities. Myosin intensity within a cell was measured as a sum intensity of all

598 pixels in a cell. Myosin concentration was calculated as myosin intensity/cell area.

599 For Figures $2 \mathrm{~K}$ and $2 \mathrm{~L}$, myosin concentration and cell size values for every cell were smoothed along

600 the time axis using a 1D gaussian filter with sigma=3 (reference ${ }^{73}$ ). For every cell at each of 25 time

601 points three values were taken: its myosin concentration, the myosin concentration in the area of 70

602 pixels around the cell boundary and the relative size change, calculated as the cell size in the next

603 time frame divided by the cell size in the current one.

604

605

\section{A visco-elastic model for the mesoderm}

606 We modelled the mesoderm as one-dimensional series of points (cell boundaries) connected by visco-elastic units (cells). Each cell behaves as a Kelvin-Voigt material made of a spring and dashpot in parallel connecting two adjacent cell boundaries (at positions $x_{i}$ and $x_{i+1}$ ). All cells have the same viscosity $(\eta)$ and stress-strain response $(S(\Delta x))$. We added 3 cells with a higher stiffness at each side of the 19 mesodermal cells to simulate the rigid ectodermal cells. Each cell contains a defined amount of "myosin" $(M)$, which exerts a force at each cell membrane position $x_{i}$ that is directly proportional to the local gradient of "myosin" around that point $\left(\nabla M\left(x_{i}\right)\right)$. The system evolves over time according to the following deterministic equation:

$$
\frac{d^{2}}{d t^{2}} x_{i}=\sum_{j} k_{i j} S\left(x_{i}-x_{j}\right)-\eta \frac{d}{d t} x_{i}+\nabla M\left(x_{i}\right)
$$
response (defined below), and the myosin profile $(M)$ is modelled as a symmetric sigmoidal function around the midline, described by the equation:

$$
M\left(x_{i}\right)=\frac{1+e^{-s w}}{1+e^{s\left(\left|x_{i}\right|-w\right)}},
$$

where $W$ and $S$ are parameters describing the width and steepness of the function, respectively, and $x_{i}=0$ corresponds to the midline (central) position of the mesoderm.

We considered 5 types of stress-strain responses models. The first corresponds to a simple linear elastic-like model, where stress increases proportionally with the strain. The other four models are non-linear, with the same stiffening response to compressive strains $(\Delta x<0)$, and 4 different types of responses to extensive strains: i) an elastomer-like model, corresponding to an elastic response but with a decreased stiffness after the proportionality limit; ii) a stiffening model, with an increased stiffness after the proportionally limit; iii) a superelastic model, corresponding to a material that undergoes strain-softening after the proportionality limit, followed by strainhardening; and iv) an elastoplastic model, with a similar curve as before, but undergoing plastic (permanent) deformation after a certain yielding stress. For simplicity, all stress-strain curves are continuous functions, with a repulsive response for compressive strains $(\Delta x<0)$ to prevent cells from having zero areas and made of connected linear segments with varying slopes (stiffness) for different ranges of extensive strains $(\Delta x>0)$. Table $\mathrm{S} 1$ contains a mathematical description of each curve, and Table S2 lists the parameters values used in our simulations. 
638 We systematically explored the outcomes of the 5 models by varying the parameters controlling the

639 myosin profile (Eq. 2).

640

\section{Microscopic model for the mesoderm}

642

We modelled a line of cells from the ventral midline to the mesectodermal cell as a series of sequentially connected actomyosin networks with varying amounts of myosin motors. Each network

644 is a 2D mesh of 800 actin filaments of $1.5 \mu \mathrm{m}$ long, randomly distributed within a rectangular region

645 of $7 \times 8 \mu \mathrm{m}$. The cells have periodic boundary conditions along the "antero-posterior" direction (top 646 to bottom in the graphic representation) and are separate by rigid but movable 'membranes'. The

647 row is bounded by unmovable walls on each end to simulate the ectoderm and the ventral midline.

648 Each membrane has 800 connecting points for the filaments on each side. Actin filaments of

649 adjacent cells do not interact except through the membrane connectors. Each cell has 1,600

650 crosslinkers and between 1,600 to 16,000 myosin motors (with a minimum level that was sufficient

651 in principle to contract the network). Both connectors are modelled as point like objects with two

652 independent hands that can bind and bridge two nearby filaments pertaining to the same cell. Once

653 bound, motor hands move towards the plus-end of the filaments until they unbind or reach and

654 detach from their ends. We used as input the parameters for the crosslinkers, connectors, motors

655 and filaments the on-off rates, movement kinetics and stiffness/persistence lengths that have been

656 biochemically determined for alpha-actinin, myosin and F-actin (see Table S3).

657 All filament-based simulations were done with $\mathrm{CytoSim}^{57}$, a cross-platform simulation engine

658 designed to handle large systems of flexible filaments and associated proteins. CytoSim uses a

659 Brownian dynamics approach to simulate the cytoskeleton, where each element is individually

660 represented in either 2D or 3D space. The number, spatial location and physical properties of each

661 element is determined at the start of the simulation and the system evolves according to the laws of

662 mechanics and stochastic reaction-kinetics.

663

\section{Data Analysis and plotting}

665 All graphs were plotted using either MATLAB (MATLAB_R2015a) or Python (version 3.6).

666 Matplotlib $^{78}$, Pandas ${ }^{79}$, Scikit-image ${ }^{80}$, NumPy $^{81}$ packages were used.The figures were compiled using

667 Adobe Illustrator CS6 (Version 16.0.0).

668

\section{Data availability}

670 Apart from the third party software tool SEGMENT3D ${ }^{74}$, all described algorithms were implemented

671 in MATLAB and are available from https://github.com/stegmaierj/CellShapeAnalysis/ (Apache

672 License 2.0) and the code for myosin analysis from https://github.com/sourabh-bhide/tissue2cells 
bioRxiv preprint doi: https://doi org/10.1101/20201015.333963; this version posted December $1,2020$. The copyright holder for this preprint (which was not certified by peer review) is the author/funder, who has granted bioRxiv a license to display the preprint in perpetuity. It is made available under aCC-BY-NC-ND 4.0 International license.

674

675

676

677

678

679

Table S2: Parameters used in the visco-elastic models

\begin{tabular}{|c|c|}
\hline Parameter & Value \\
\hline$k_{c}$ & 131.247 \\
\hline$x_{c}$ & 6 \\
\hline$n$ & 0.05 \\
\hline$s_{1}$ & 1.0 \\
\hline$s_{2 e m}$ & 0.2 \\
\hline$S_{2 s}$ & 2.0 \\
\hline$s_{2 s e}$ & -0.75 \\
\hline$S_{3 s e}$ & 0.2 \\
\hline$s_{2 e p}$ & -1.25 \\
\hline$s_{3 e p}$ & 0.2 \\
\hline
\end{tabular}

Table S1: Description of equations used for the visco-elastic stress-strain responses

\begin{tabular}{|c|c|c|c|c|}
\hline \multirow{2}{*}{ Stress-strain type } & \multicolumn{4}{|c|}{ Strain range } \\
\cline { 2 - 5 } & $\Delta x<0$ & $\Delta x<x_{p l}$ & $\Delta x<x_{s h}$ & $x_{s h}<\Delta x$ \\
\cline { 2 - 5 } & function & slope & slope & slope \\
\hline Linear & $\Delta x s_{1}$ & $s_{1}$ & $s_{1}$ & $s_{1}$ \\
\hline Elastomeric & $k_{c}\left[x_{c}^{-n}-\left(\Delta x+x_{c}\right)^{-n}\right]$ & $s_{1}$ & $s_{2 e m}$ & $s_{2 e m}$ \\
\hline Stiffening & $k_{c}\left[x_{c}^{-n}-\left(\Delta x+x_{c}\right)^{-n}\right]$ & $s_{1}$ & $s_{2 s}$ & $s_{2 s}$ \\
\hline Superelastic & $k_{c}\left[x_{c}^{-n}-\left(\Delta x+x_{c}\right)^{-n}\right]$ & $s_{1}$ & $s_{2 s e}$ & $s_{3 s e}$ \\
\hline Elastoplastic & $k_{c}\left[x_{c}^{-n}-\left(\Delta x+x_{c}\right)^{-n}\right]$ & $s_{1}$ & $s_{2 e p}$ & $s_{3 e p}$ \\
\hline
\end{tabular}

680

681 


\begin{tabular}{|l|c|c|c|}
\hline motors per cell & $\mathrm{N}_{\mathrm{m}}$ & $1600-16000$ & - \\
\hline Crosslinker & & & \\
binding rate & $\mathrm{k}_{\mathrm{xb}}$ & 10 & $\mathrm{~s}^{-1}$ \\
binding range & $\mathrm{r}_{\mathrm{xb}}$ & 0.1 & $\mu \mathrm{m}$ \\
unbinding rate & $\mathrm{k}_{\mathrm{xu}}$ & 0.3 & $\mathrm{~s}^{-1}$ \\
stiffness & $\mathrm{s}_{\mathrm{x}}$ & 500 & $\mathrm{pN} / \mu \mathrm{m}$ \\
crosslinkers per cell & $\mathrm{N}_{\mathrm{x}}$ & 1600 & - \\
\hline Membrane connectors & & & \\
binding rate & $\mathrm{k}_{\mathrm{cb}}$ & 2000 & $\mathrm{~s}^{-1}$ \\
binding range & $\mathrm{r}_{\mathrm{cb}}$ & 0.1 & $\mu \mathrm{m}$ \\
unbinding rate & $\mathrm{k}_{\mathrm{cu}}$ & 0 & $\mathrm{~s}^{-1}$ \\
stiffness & $\mathrm{s}_{\mathrm{c}}$ & 500 & $\mathrm{pN}$ \\
connectors per membrane & $\mathrm{N}_{\mathrm{cm}}$ & 400 & - \\
connectors per wall & $\mathrm{N}_{\mathrm{cw}}$ & 800 & - \\
\hline
\end{tabular}

684 Table S4: List of Fly Stocks

\begin{tabular}{|c|c|c|}
\hline Stock & source & Reference \\
\hline w[*]; p[UAS-sqh-Gap43::mCherry]/CyO; + & Thomas Lecuit & 13 \\
\hline $\begin{array}{l}\text { w[*]; p[sqh-MRLC::eGFP]/Cyo; p[UASp- } \\
\text { Gap43::mCherry]/MKRS }\end{array}$ & Thomas Lecuit (sqh-GFP) & 75 \\
\hline $\begin{array}{l}\text { sqh }^{A X 3} ; p[s q h-U t r o p h i n A B D:: G F P], ~ p[s q h- \\
\text { MRLC::mCherry] }\end{array}$ & $\begin{array}{l}\text { Thomas Lecuit (sqh- } \\
\text { mCherry) }\end{array}$ & 12 \\
\hline sqh $^{\mathrm{AX}} ; \mathrm{p}$ [sqh-MRLC::mCherry[; [Spider::GFP] & Stefano DeRenzis & 13 \\
\hline $\mathrm{w}\left[{ }^{*}\right] ; \mathrm{p}[$ snail::MS2]; + & Jacques Bothma & 70 \\
\hline $\begin{array}{l}\mathrm{w}\left[{ }^{*}\right] ; \mathrm{p}[\mathrm{MCP}:: \mathrm{mCherry}] / \text { CyO ; } \\
\mathrm{p}[\mathrm{MCP}:: \mathrm{mCherry}] / \mathrm{TM} 3, \text { Ser }\end{array}$ & Jacques Bothma & 76 \\
\hline $\begin{array}{l}\mathrm{w}\left[{ }^{*}\right] ;+; \mathrm{P}[\mathrm{w}+, \mathrm{UASp}-\mathrm{mCherry}:: \mathrm{CRY} 2-\mathrm{OCRL}] / \\
\mathrm{Sb}\end{array}$ & Stefano DeRenzis & 59 \\
\hline $\begin{array}{l}\mathrm{w}\left[{ }^{*}\right] ; \mathrm{P}[\mathrm{w}+, \mathrm{UASp}-\mathrm{CIBN}:: p m G F P] / / C y o ; \\
\mathrm{sb} / \mathrm{TM} 3, \mathrm{Sb}\end{array}$ & Stefano DeRenzis & 59 \\
\hline $\mathrm{w}\left[{ }^{*}\right] ; \mathrm{p}[\mathrm{MCP}:: \mathrm{GFP}]$ & Stefano DeRenzis & 77 \\
\hline $\mathrm{w}\left[{ }^{*}\right] ; \mathrm{p}[\mathrm{Sim}:: \mathrm{MS} 2]$ & Stefano DeRenzis & $\begin{array}{ll}69 \\
\end{array}$ \\
\hline $\mathrm{w}\left[{ }^{*}\right] ;$ p[UASp-RhoGEF2-CRY2]/TM3, Ser & Stefano DeRenzis & 10 \\
\hline $\begin{array}{l}\text { p[sqh::GFP];p[w+,mat } \alpha \text { Tub- } \\
\text { Gal4::VP16],p[UASp- } \\
\text { Gap43::mCherry::mCherry]/TM3 }\end{array}$ & Adam Martin & 49 \\
\hline w[*]; If/CyO; p[Oskp-Gal4::VP16]/TM3, Ser & Bloomington stock 23651 & \\
\hline $\mathrm{p}[\mathrm{sqh}>$ Gap43::mCherry]; +; + & Stefano DeRenzis & 10 \\
\hline
\end{tabular}




\begin{tabular}{|l|l|}
\hline Product name & Product information \\
\hline Glass bottom plates & Matek corporation (Part no.: P35G-1.5-10.C) \\
\hline Microspheres & $\begin{array}{l}\text { TetraSpeck }{ }^{\text {TM }} \text { Fluorescent Microspheres, ThermoFisher } \\
\text { (Catalogue no.:T7284) }\end{array}$ \\
\hline Gelrite & Merck (Catalogue no.:G1910) \\
\hline Halocarbon Oil 27 & Merck (Catalogue no.:H8773) \\
\hline
\end{tabular}

689

690

Table S6: Primers

\begin{tabular}{|l|l|}
\hline Name & Sequence \\
\hline Tubulin promoter Forward & 5'-tcatctaggcctgaattcgatatcaagcttgcac-3' \\
\hline Tubulin promoter Reverse & 5'-tcatctgcggccgcgtaccttcacgctgtgg-3' \\
\hline GAP43mCardinal Forward & $\begin{array}{l}\text { 5'-aaatatgcggccgccaccatgctgtgctgtatgcgaagaaccaaac } \\
\text { aggttgaaaaaaatgatgaggaccaaaagattatggtgagcaagggcgag-3' }\end{array}$ \\
\hline GAP43mCardinal Reverse & 5'-tcacgcggatccttacttgtacagctcgtccatg-3' \\
\hline
\end{tabular}

691

692

693 Table S7: List of genotypes used in experiments

\begin{tabular}{|c|c|c|}
\hline Figure no. & Fly stock/ Cross & Microscopy \\
\hline $1 \mathrm{C}-\mathrm{C}^{\prime \prime}, \mathrm{D}-\mathrm{D}^{\prime \prime} ; \mathrm{S} 1 \mathrm{~A}-\mathrm{C}$ & $\mathrm{p}[$ mat tub >GAP43::mCardinal]/CyO & MuVi SPIM \\
\hline $1 \mathrm{E}, \mathrm{E}^{\prime} ; 2 \mathrm{E}-\mathrm{G}$ & $\mathrm{sqh}^{\mathrm{AX} 3} ; \mathrm{p}[\mathrm{sqh}-\mathrm{MRLC}:: \mathrm{mCherry}] ; \mathrm{p}[$ Spider::GFP] & LSM 880 \\
\hline $1 \mathrm{I}, \mathrm{I}$ '; S2; S3 & $\begin{array}{l}\text { sqh }^{A X 3} ; p[s q h-U t r o p h i n A B D:: G F P], p[s q h- \\
\text { MRLC::mCherry] }\end{array}$ & LSM 880 NLO \\
\hline $3 A-B, C-D, S 1$ D-I & $\begin{array}{l}\text { sqh-MRLC::eGFP/MCP::mCherry;UASp- } \\
\text { Gap43::mCherry/MCP::mCherry X Snail } \\
\text { MS2/SnailMS2 }\end{array}$ & LSM 780 NLO \\
\hline $3 \mathrm{H}-\mathrm{K}$ & $\begin{array}{l}\text { ClBNpm::GFP/MCP::GFP; } \\
\text { OCRLCRY2::mCherry/osk Gal4 X Sim-MS2/Sim- } \\
\text { MS2 }\end{array}$ & LSM 780 NLO \\
\hline 4 & $\begin{array}{l}\text { sqhp-Gap43::mCherry/+; UASp>CIBN::pmGFP; } \\
\text { UASp>RhoGEF2-CRY2 / Osk>Gal4::VP16 }\end{array}$ & LSM 780 NLO \\
\hline S2 A-D & $\begin{array}{l}\mathrm{sqh}^{\mathrm{AX}} ; \mathrm{p}[\mathrm{sqh}-U \text { trophinABD::GFP], } \mathrm{p}[\mathrm{sqh}- \\
\text { MRLC::mCherry] }\end{array}$ & MuVi SPIM \\
\hline S6 & sqh $^{\mathrm{AX} 3} ; \mathrm{p}[\mathrm{sqh}-\mathrm{MRLC}:: \mathrm{mCherry}[; \mathrm{p}[$ Spider::GFP] & LSM 880 \\
\hline
\end{tabular}

694 
bioRxiv preprint doi: https://doi org/10.1101/2020.10.15.333963; this version posted December 1, 2020. The copyright holder for this preprint (which was not certified by peer review) is the author/funder, who has granted bioRxiv a license to display the preprint in perpetuity. It is made available under aCC-BY-NC-ND 4.0 International license.

695

696

697

\section{Main figures}

Figure 1

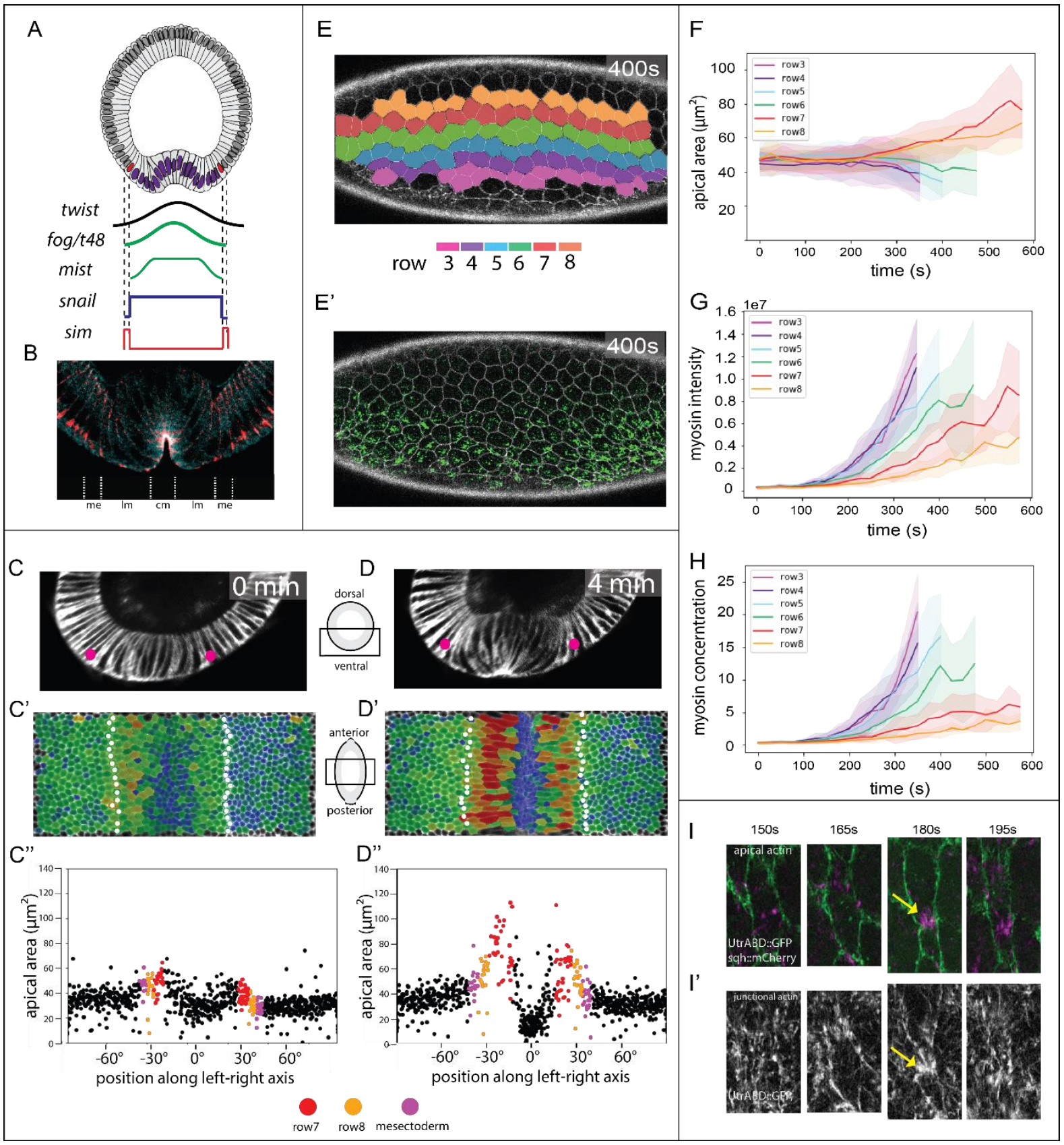

Fig. 1 Cell activities during ventral furrow formation.

(A) Genes expressed ventrally at the onset of gastrulation.

702 Top: Diagram of a cross-section through an embryo at the beginning of gastrulation. Mesodermal 703 nuclei expressing Snail: blue, mesectodermal nuclei with single-minded: red.

704 Bottom: Schematic of gene expression levels. Twist (black) and Snail (blue) regulate the genes that 705 control shape changes (fog, T48, mist).

706 (B) Section of an embryo stained for beta-catenin/armadillo to visualize adherens junctions (pink) 707 and myosin (blue). Junctions in the central $(\mathrm{cm})$ and lateral $(\mathrm{Im})$ mesoderm are apical, the 
708 mesectodermal (me) cell has one on apical and one subapical junction, ectodermal junctions are

709 subapical ${ }^{25}$.

710 (C, -D) Cross-sectional views at two time points from a MuVi-SPIM recording of an embryo expressing

711 GAP43::mCardinal (membrane). Pink dots: mesectoderm. timeseries in Suppl. Fig.1

$712\left(C^{\prime}, D^{\prime}\right)$ Apical surface 'peels' with colour-coded apical cell areas. Mesectoderm: white dots.

713 ( $\left.C^{\prime \prime}, D^{\prime \prime}\right)$ Apical area from $C^{\prime}$ and $D^{\prime}$ plotted against cell position $\left(0^{\circ}\right.$ is the ventral midline). Each dot

714 represents one cell. Colour-code for rows 7,8 as in $\mathrm{E}$, mesectoderm magenta.

715 (E) Ventro-lateral views of a confocal recording of an embryo expressing Spider::GFP (white) and 716 sqh::mCherry (green) at a confocal Z-plane $3 \mu \mathrm{m}$ below the surface (Suppl. Movie 2).

717 (E') Cells were segmented using Spider::GFP and assigned to colour-coded rows.

718 (F-H) Apical areas, total myosin intensity and myosin concentration plotted per row against time

719 (mean and standard deviation). Tracks for ventral rows stop early because the cells are lost from the

720 imaging plane .

721 (I-I') Example of a lateral mesodermal cell at four time-points in an embryo expressing utrABD::GFP

722 (subapical for cell outlines in I, green; apical in I'; white) and sqh::mCherry (magenta) during

723 formation of a myosin focus. Arrow: local cortical deformation. 
bioRxiv preprint doi: https://doi.org/10.1101/2020.10 15.333963 this version posted December 1, 2020. The copyright holder for this preprint (which was not certified by peer review) is the author/funder, who has granted bioRxiv a license to display the preprint in perpetuity. It is made available under aCC-BY-NC-ND 4.0 International license.

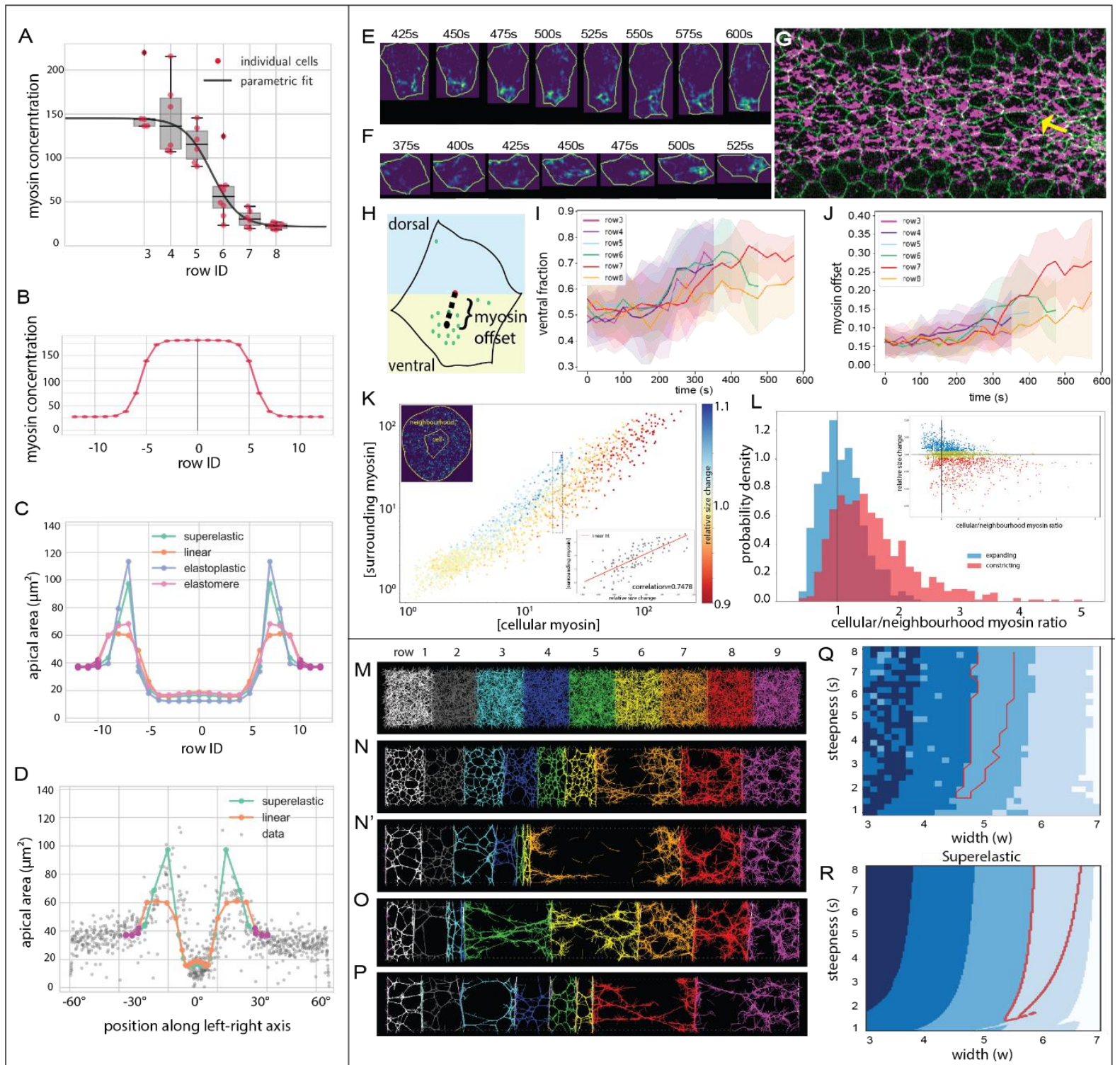

Fig. 2. Computational models and myosin distribution.

(A-D) Viscoelastic model of a line of cells.

728 (A) Polynomial fit to the myosin concentration per row, measurements from embryo 1.

729 (B) The model is driven by an explicit contractility value for each cell.

730 (C) Final cell lengths for linear elastic, elastomeric and elastoplastic spring constants. Magenta dots

731 represent the stiffer ectoderm.

732 (D) Values for two curves from (C) superimposed on measured cell sizes. The point for each value is

733 shifted along the $x$-axis from the starting point represented in $(C)$ to the position where each cell row 734 has moved at this time point.

735 (E) Example of myosin dynamics in a single cell from row 8. Cell contours and myosin signal pixels 736 were isolated using individual cell segmentation masks. Myosin intensity values increase from blue to 737 yellow.

738 (F) Example of an incompletely constricted central mesodermal cell (arrow in G).

739 (G) Embryo 2, ventral view. Green: membranes; magenta: myosin. 
740 (H) Representation of myosin spatial distribution in a cell. 'Offset' is the Euclidean distance between

741 the cell centroid and the intensity-weighted centroid of the myosin signal; 'DV asymmetry' is the

742 ratio of myosin pixels in the ventral half of the cell to the total number of myosin pixels in the cell.

743 (I) Average proportion of myosin in the ventral half of the cell, plotted over time for each row.

744 (J) Offset of myosin centroid from cell centroid, average per row.

745 (K) Myosin concentration within a cell plotted versus surrounding myosin concentration in a ring

746 around the cell (radius of 70 pixels $(\sim 8.5 \mu \mathrm{m})$ from each point of the cell periphery; top left inset),

747 with the change in cell size over two consecutive frames indicated in colour. All segmented cells at 25

748 time points from movie 5 are represented. The bottom right inset shows the cells with internal

749 concentrations at values between 18 and 22 (boxed in the main plot) with surrounding concentration

750 plotted against size change.

751 (L) Change in cell size compared to the ratio of cell-intrinsic over surrounding myosin concentration.

752 The top right insert shows a plot of all individual cells, with colour illustrating the bins used for the

753 main density histogram (blue: expanding; red: contracting; yellow: no significant change, not

754 represented in the histogram). All cells with concentrations above 45 constrict, regardless of the

755 levels in surrounding cells. The proportion of expanding cells is greater at low intrinsic-to-

756

757 surrounding levels, and is highest when this ratio drops below one (i.e. surrounding cells have more myosin).

758 (M-Q) Microscopic model of a line of cells with a contractile actomyosin meshwork.

759 (M) Initial condition of the system with randomly distributed actin, crosslinkers and myosin motors

760 within each cell (shown with different colors).

761 (N-N') Example of a simulation with myosin profile that qualitatively reproduces experimental

762 results.

763 (O-P) Examples of simulations where the myosin profile was wider (M) or shorter (N).

764 (Q-R) Parameter map for myosin concentration curves with varying peak widths and steepnesses for microscopic ( $Q$ ) and visco-elastic (R) with super-elastic models. Blue shades: number of expanding cells. Red outline: conditions where the three right cells expand with an inverted pattern of stretching that qualitatively matches experiments. 
bioRxiv preprint doi: https://doi.org/10.1101/2020.10.15.333963; this version posted December 1, 2020. The copyright holder for this preprint (which was not certified by peer review) is the author/funder, who has granted bioRxiv a license to display the preprint in perpetuity. It is made available under aCC-BY-NC-ND 4.0 International license.
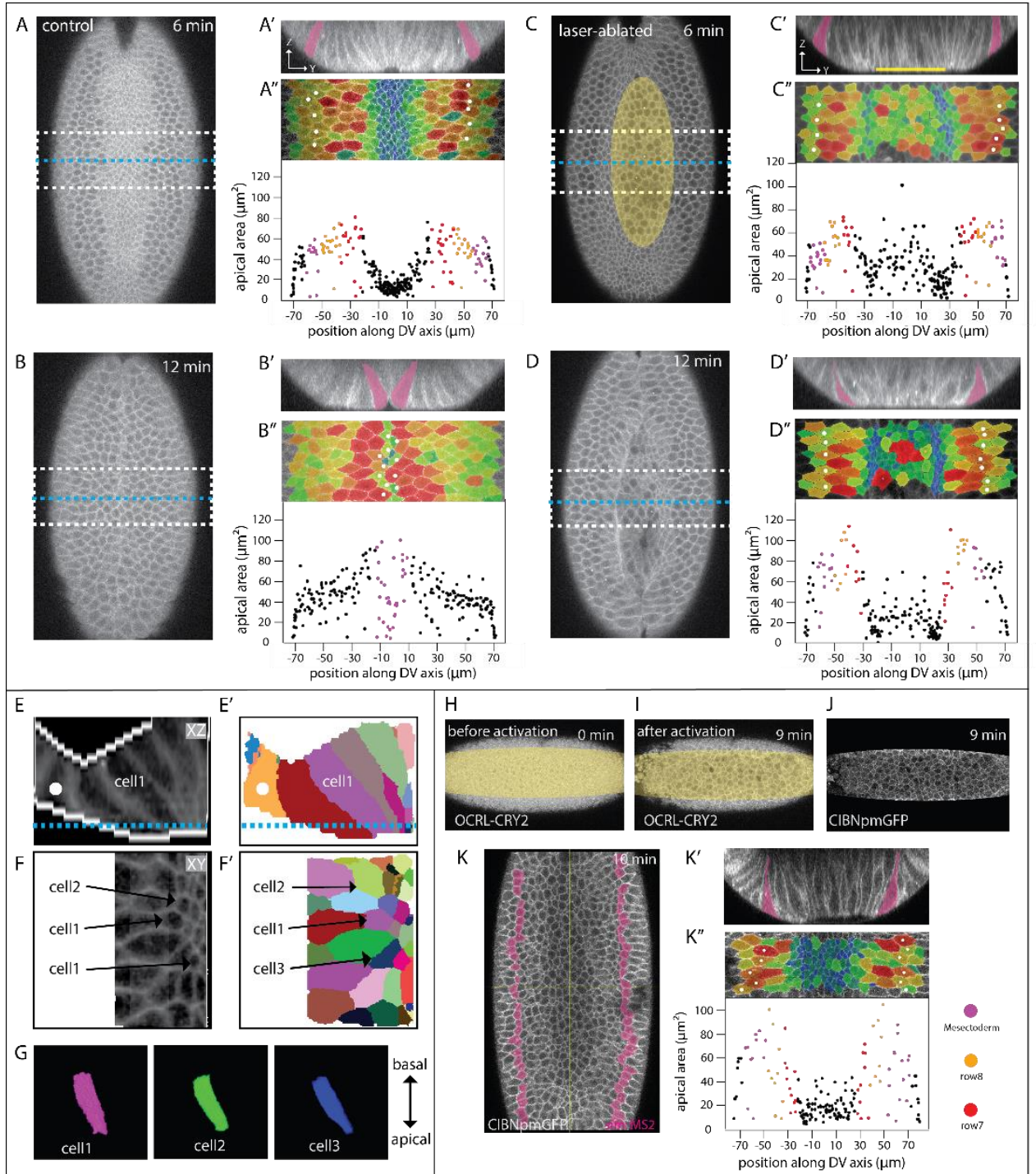

Fig 3. Effects of restricting apical constriction in central cells.

(A - D) Two time-points from confocal recordings of control (A, B) and laser-manipulated (C, D) embryos expressing GAP43::mCherry (cell outlines). SnailMS2 and MCP::mCherry (not shown) were used to determine the extent of the mesoderm; mesectoderm is marked by magenta fill in $A^{\prime}-D^{\prime \prime}$ and white spots in $A^{\prime \prime}-D^{\prime \prime} .0$ sec is the point when the apical-basal length of the central rows is $35 \mu \mathrm{m}$. The region marked in yellow in (C) was repeatedly illuminated with an infrared laser. See also Suppl. video 3.

779 (A-D) Confocal Z-planes $15 \mu \mathrm{m}$ below the ventral surface. Positions of Z-sections in $A^{\prime}-D^{\prime}$ are marked 780 by yellow lines and the region of the apical surface peels in $A^{\prime \prime}-D^{\prime \prime}$ by white boxes. $\left(A^{\prime}-D^{\prime}\right)$ Z-sections at the positions indicated in A - D.

$782\left(A^{\prime \prime}-D^{\prime \prime}\right)$ Apical surface peels of regions marked in A - D. Same markings as in figure 1, with 783 quantification of the apical areas of the cells plotted against their position. Same representation of cell size as in Fig. 1. Note data points at the sides include artefactually small values because cells at the edge are not full size. $(E-G) 3 D$ segmentation of I cells from the embryos in (D). 
787 (E) Z-section showing cell outlines and the binary mask used for segmentation (white edges). Blue

788 line indicates position of Z-section shown in F. Mesectoderm: white spot. (E') segmentation result.

789 (F) Z-plane and ( $F^{\prime}$ ) segmentation result. The numbers indicate the cells shown in 3D below.

790 (G) 3D renderings of the three cells marked above (F, F'). For 3D viewing see Supplementary movies.

791 See also Suppl. video 4.

792 ( $\mathrm{H}-\mathrm{K}$ ) Optogenetic inactivation of cortical actomyosin in a ventrally mounted embryo co-expressing

793 OCRL-CRY2::mCherry, CIBN::pmGFP and simMS2 and MCP::GFP to mark the mesectoderm

$794(\mathrm{H}-\mathrm{J})$ Confocal Z-planes $5 \mu \mathrm{m}$ below the surface before and after laser-illumination to release

795 actomyosin from the apical cortex. Illumination leads to recruitment of OCRL-CRY2 to the plasma

796 membrane (compare $\mathrm{H}$ and $\mathrm{I}$ ) via membrane-associated CIBN::pmGFP.

797 (K) Z-plane $25 \mu \mathrm{m}$ below the ventral surface $10 \mathrm{~min}$ after laser treatment to show the position of the 798 edge of the mesoderm. Mesectoderm in magenta. This level does not show the apical surface.

799 ( $\left.\mathrm{K}^{\prime}\right)$ Cross-section showing non-stretched cells adjacent to the mesectoderm (magenta).

800 (K") Apical surface peel and quantification of apical cell areas. Same markings as above. 

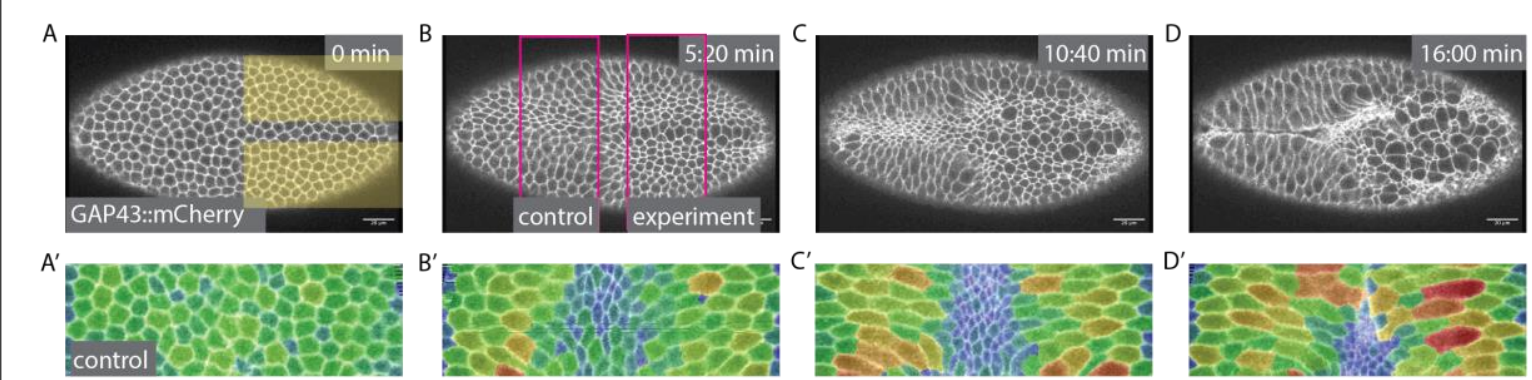

$A^{\prime \prime}$
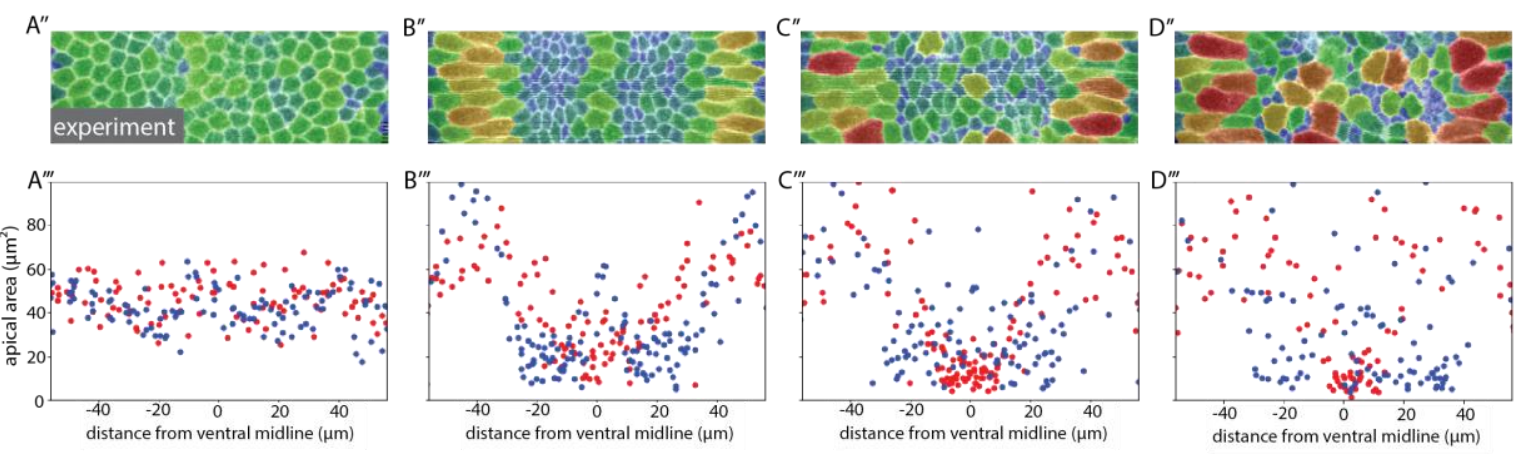

803

804

Fig 4. Effect of ectopic myosin recruitment.

805

(A-D) Confocal Z-planes $5 \mu \mathrm{m}$ below the surface of an embryo co-expressing GAP43mCherry,

806 CIBN::pmGFP and RhoGEF2-CRY2. Photoactivation in the yellow areas in (A) induces membrane-

807 recruitment of RhoGEF2-CRY2. Magenta lines in (B) show control and experimental areas analysed.

808 $\left(A^{\prime}-D^{\prime}, A^{\prime \prime}-D^{\prime \prime}\right)$ Apical surface peels of the regions marked in (B) overlaid with colour-code

809 representing relative apical areas.

810 ( $\left.A^{\prime \prime \prime}-D^{\prime \prime \prime}\right)$ Apical areas of the cells in the control (red dots) and experimental (blue dots) parts of the 811 embryo plotted against their positions. 
bioRxiv preprint doi: https://doi org/10.1101/2020 10 15.333963. this version posted December 1,2020 . The copyright holder for this

preprint (which was not certified by peer review) is the author/funder, who has granted bioRxiv a license to display the preprint in perpetuity. It is made available under aCC-BY-NC-ND 4.0 International license.

\section{Supplementary figures}

\section{Supplementary Figure 1}

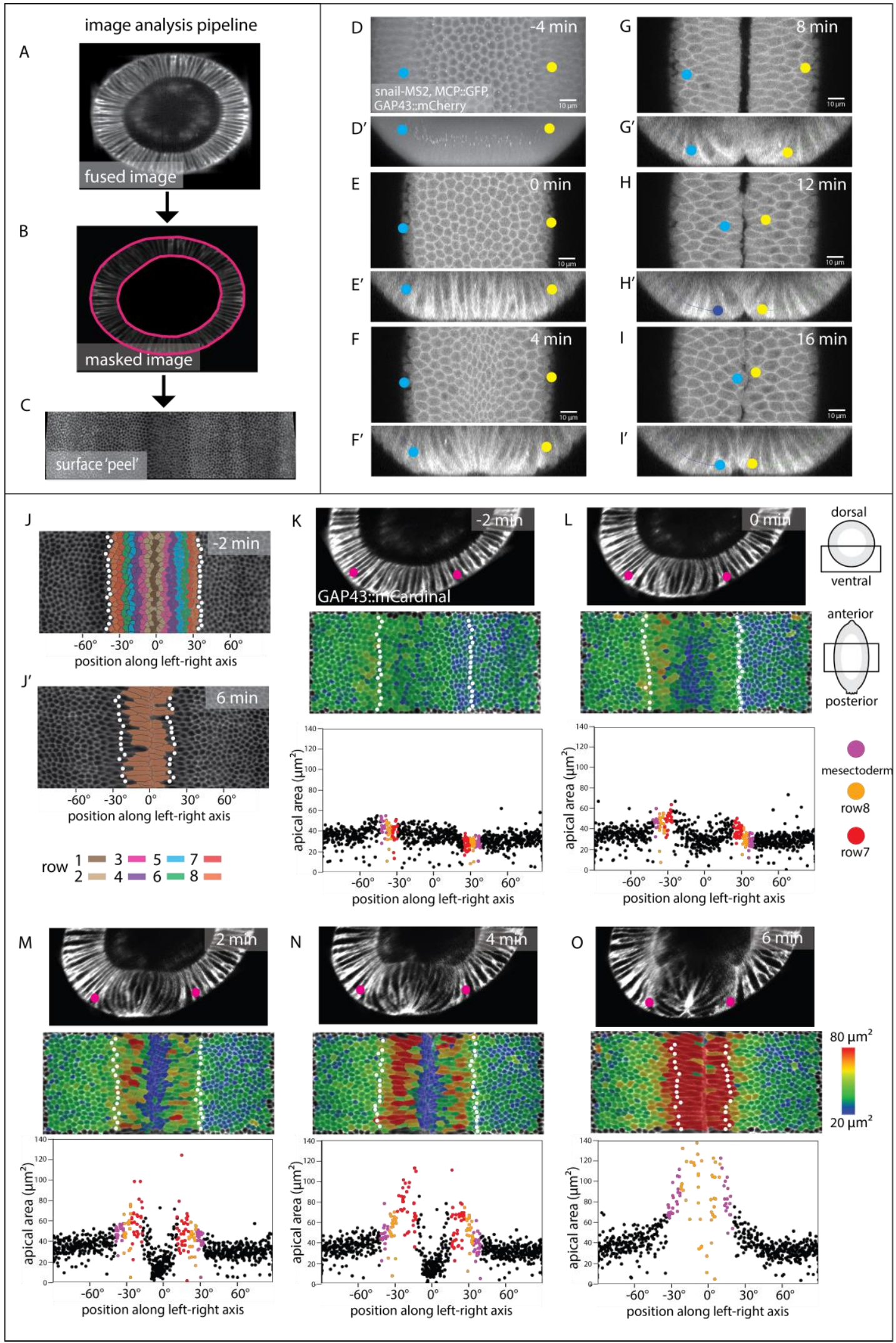

815

816 Suppl. Fig. 1. Image analysis and identification of the edge of the mesoderm 
817 (A) Embryos were imaged using Multi-View SPIM. The resulting data sets were fused into a single 3D

818 stack for each timepoint. Ventral side top left.

819 (B, C) Apical (outside) and basal surface masks were defined semi-automatically. These masks were 820 then used to extract the apical surface of the embryo ${ }^{36}$.

821 (D, $\left.D^{\prime}\right)$ Maximum intensity projections along the apical-basal (D) and anterior-posterior $\left(D^{\prime}\right)$ direction

822 of an embryo co-expressing GAP43::mCherry, Snail::MS2 and MCP::mCherry 4 min before the

823 initiation of ventral furrow formation. The white spots represent sites of snail::MS2 RNA in the nuclei

824 of mesodermal cells. Yellow and blue dots mark the positions of the adjacent mesectodermal cell

825 rows.

826 (E-I) Confocal Z-plane $2 \mu \mathrm{m}$ from the surface and Z-sections $\left(E^{\prime}-I^{\prime}\right)$ over the course of furrow

827 invagination. The mesectodermal cell rows meet at the midline. Back-tracing from this time point can

828 be used to determine the edge of the mesoderm in unmarked embryos.

$829\left(\mathrm{~J}, \mathrm{~J}^{\prime}\right)$ Surface peels extracted from MuVi SPIM images at -2 and 6 min from initiation of ventral

830 furrow formation. White dots indicate the mesectodermal cells as determined by backtracing. Cell

831 rows are colour-coded with numbering coordinated operationally around row 6 , which is the last

832 non-stretching row and easily identifiable in all movies, regardless of imaging angle. The width of the

833 mesoderm varies along the anterior-posterior axis, with a width of less than 18 cells in some areas.

834 (K-O) Each panel is from one time-point from a MuVi SPIM recording of an embryo expressing

835 GAP43::mCardinal, with three of the three images showing first, cross-sectional views; secondly,

836 apical surface 'peels' extracted from the ventral half of the central one third of the embryo, And

837 finally and third, the apical areas plotted against cell position along the left-right axis (the centre, $0^{\circ}$,

838 is the ventral midline of the embryo). Each dot represents one cell. Apical cell areas measured from

839 segmented images were colour-coded and overlayed on the original image. Mesectodermal cells are

840 marked as white dots in the surface peels and as magenta dots in the plots. For the description in

841 this figure, we define $\mathrm{t}=0 \mathrm{~min}$ as the time when cells in the central four rows have constricted on

842 average by at least $20 \%$. 


\section{Supplementary Figure 2}
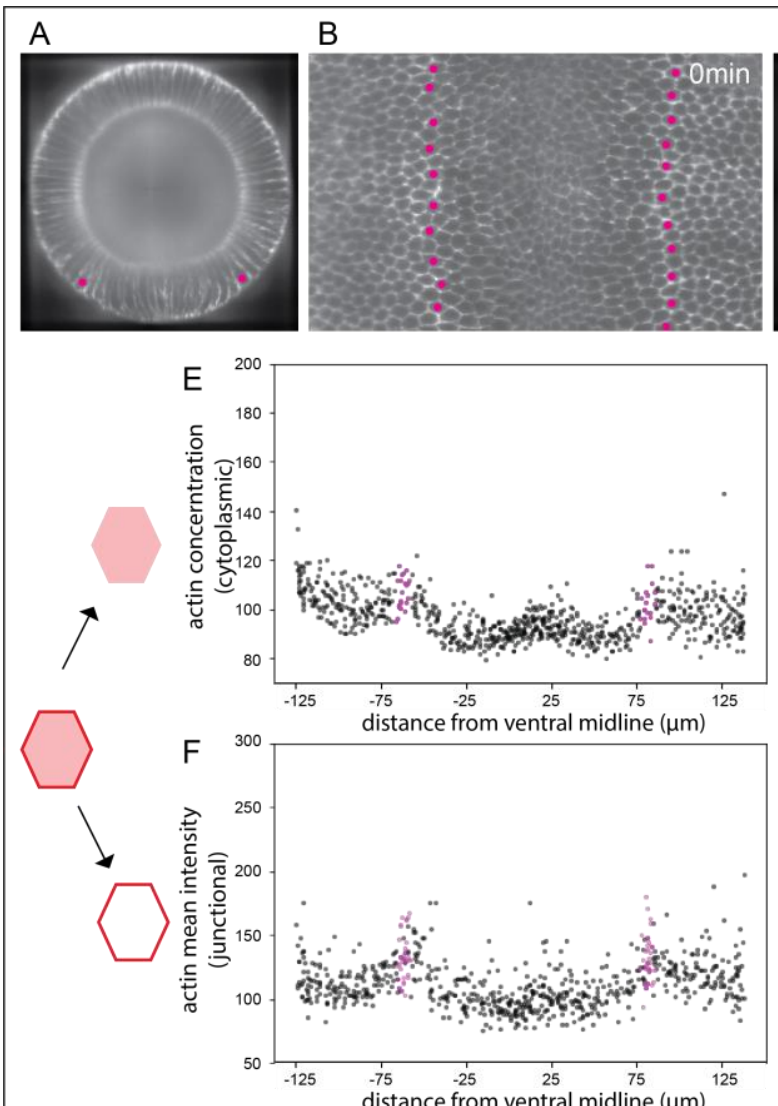

distance from ventral midline $(\mu \mathrm{m})$
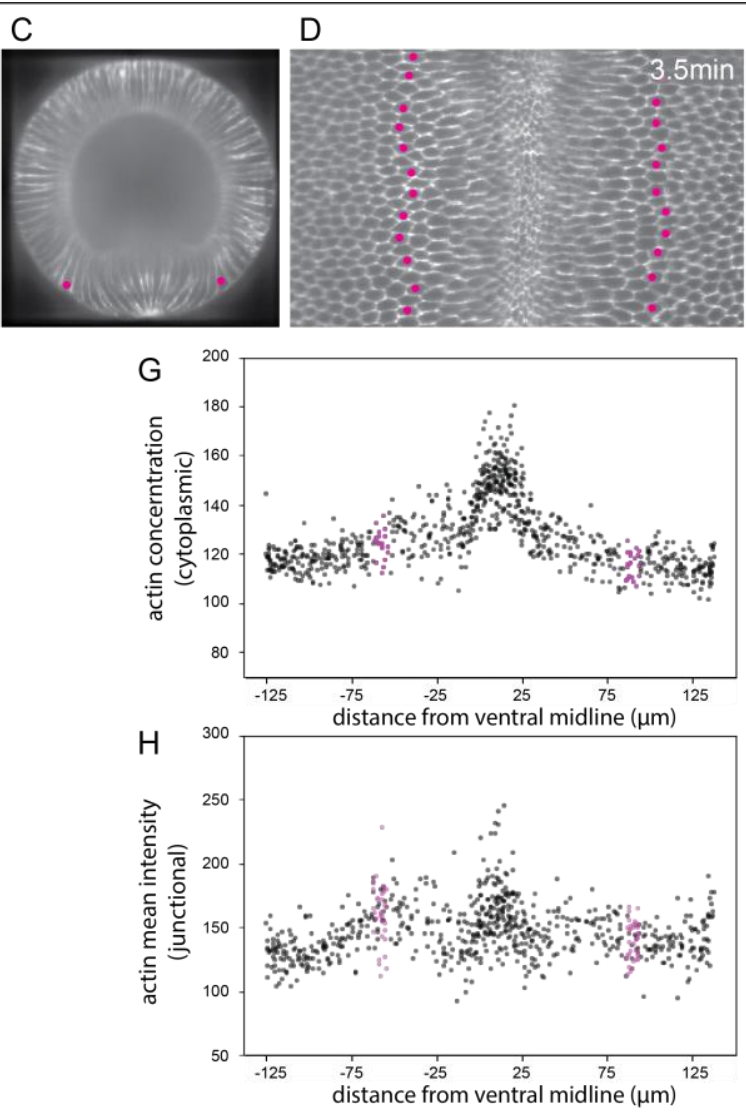

846

847

Suppl. Fig. 2. Distribution of apical F-actin in the mesoderm.

848 (A-H) Data from MuVi SPIM recordings of an embryo expressing UtrABD::GFP to visualize F-actin. The rows of mesectodermal cells (identified by back-tracing) are marked in magenta

850 (A,C) Cross sectional view at $~ 50 \%$ egg length and (B,D) sub-apical peel extracted $2 \mu \mathrm{m}$ below the apical surface. $(\mathrm{E}-\mathrm{H})$ From the segmented subapical peel, the F-actin mean cytoplasmic concentration (sum of all pixel intensities divided by area) and mean junctional intensity (sum of all pixel intensities divided by length of the junction) are plotted for every cell in the area shown. The mean cytoplasmic intensity and the mean junctional intensity are lower in the mesodermal cells than the ectodermal 
bioRxiv preprint doi: https://doi org/10.1101/2020 10.15.333963. this version posted December 1, 2020. The copyright holder for this

preprint (which was not certified by peer review) is the author/funder, who has granted bioRxiv a license to display the preprint in perpetuity. It is made available under aCC-BY-NC-ND 4.0 International license.

Supplementary Figure 3

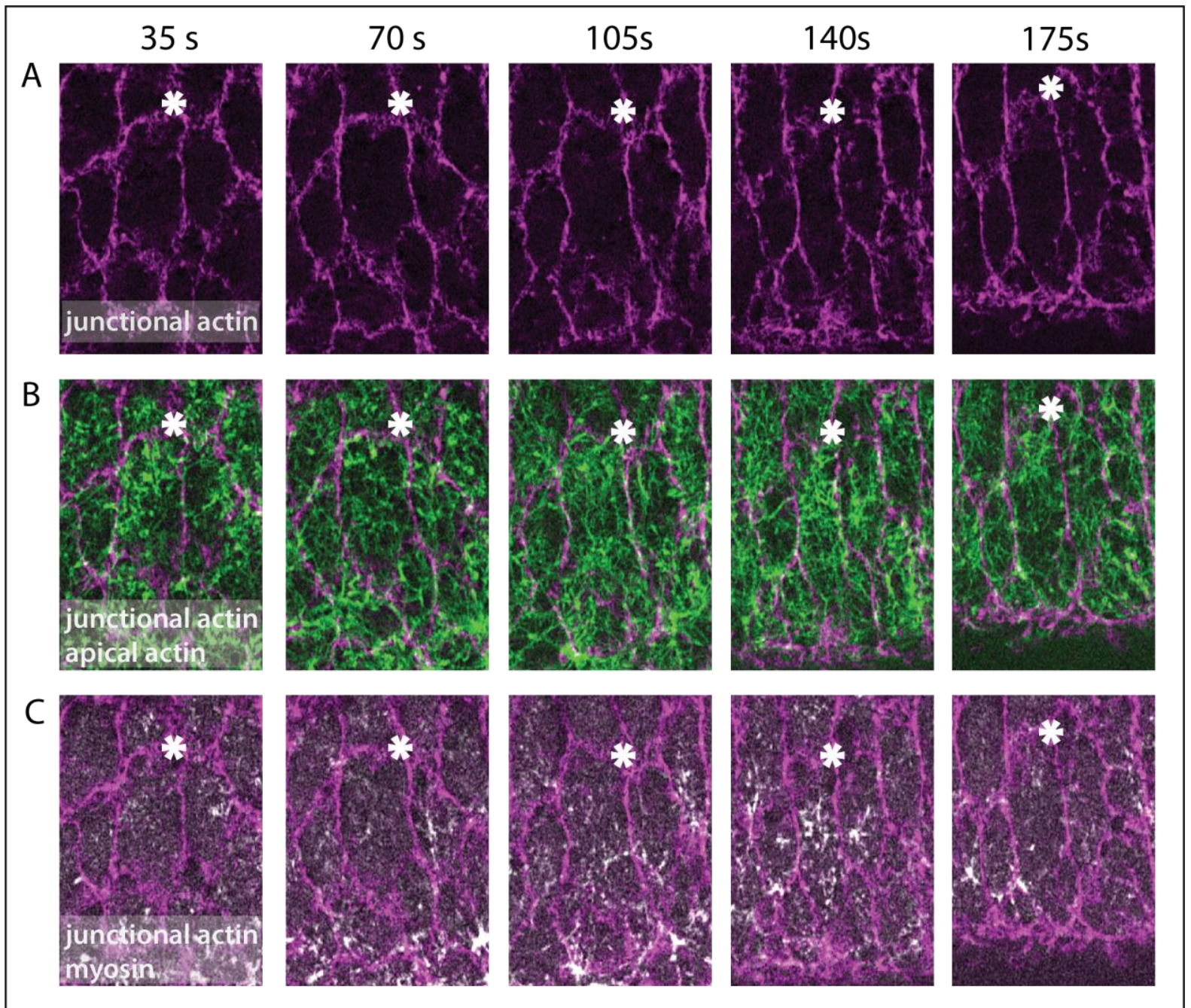

Suppl. Fig. 3. Apical actomyosin meshwork in an expanding lateral cell.

860 Ventro-laterally mounted embryo (same as shown in Fig. 1I-I') expressing utrABD::GFP and

861 sqh::mCherry to visualise F-actin and myosin.

862 (A) junctional actin in a confocal section $3 \mu \mathrm{m}$ from the surface.

863 (B) apical cortical actin meshwork (green; sum intensity Z-projection of confocal sections within $1 \mu \mathrm{m}$

864 from surface) and subapical junctional actin (magenta) to visualize cell boundaries.

865 (C) sum intensity Z-projections of confocal sections within $1 \mu \mathrm{m}$ from surface for apical myosin (red)

866 junctional subapical junctional actin (magenta) to visualize cell boundaries.

867 The white asterisk is a reference point. 
bioRxiv preprint doi: https:/doi org/10.1101/2020 10.15.333963; this version posted December 1, 2020. The copyright holder for this preprint (which was not certified by peer review) is the author/funder, who has granted bioRxiv a license to display the preprint in perpetuity. It is made available under aCC-BY-NC-ND 4.0 International license.

A sqh::mCherry
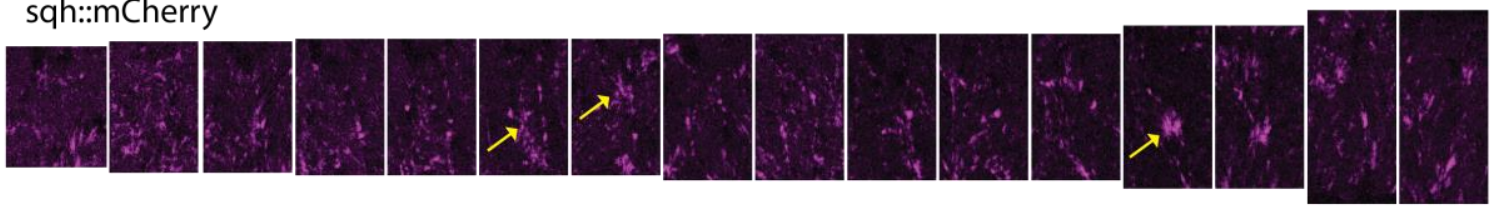

B utrABD::GFP
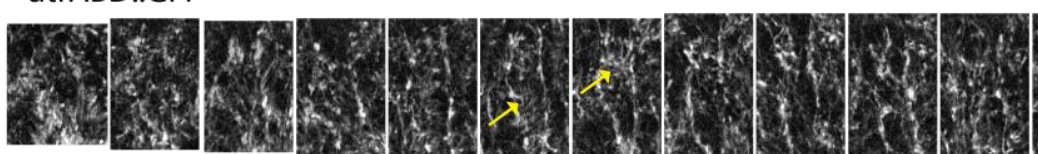

C sub-apical actin+sqh::mCherry
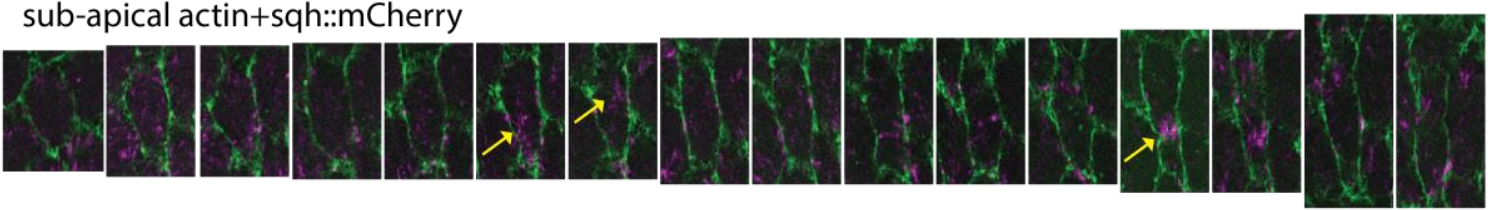

$0 \mathrm{~s} \quad 15 \mathrm{~s}$

$30 \mathrm{~s} \quad 45$

$60 \mathrm{~s} \quad 75$

$90 \mathrm{~s} \quad 105 \mathrm{~s}$

$120 \mathrm{~s} \quad 135 \mathrm{~s}$

$150 \mathrm{~s} \quad 165 \mathrm{~s} \quad 180 \mathrm{~s} \quad 195 \mathrm{~s}$

870

Suppl. Fig 4. Pulsatile actomyosin meshwork in lateral mesodermal cell.

872 Example of a stretching lateral mesodermal cell in a ventro-laterally mounted embryo (same as

873 shown in Fig. 1I-I') expressing UtrABD::GFP (white) and sqh::mCherry (magenta).

874 (A, B) Sum intensity projections of myosin (A) and apical actin (B) in the first $2 \mu \mathrm{m}$ below the surface.

875 (C) Subapical cortical F-actin ( $2.5 \mu \mathrm{m}$ below the surface; green) marks the cell boundaries. Acto-

876 myosin foci form twice (yellow arrows, $75 \mathrm{sec}$ and $180 \mathrm{sec}$ ) and create a constriction in the anterior-

877 posterior direction. 


\section{Supplementary Figure 5}

879

880

881

882

883

884

885

886

887

888

889

890

891

892

893

894

895

896

897

898

899

900

901

902

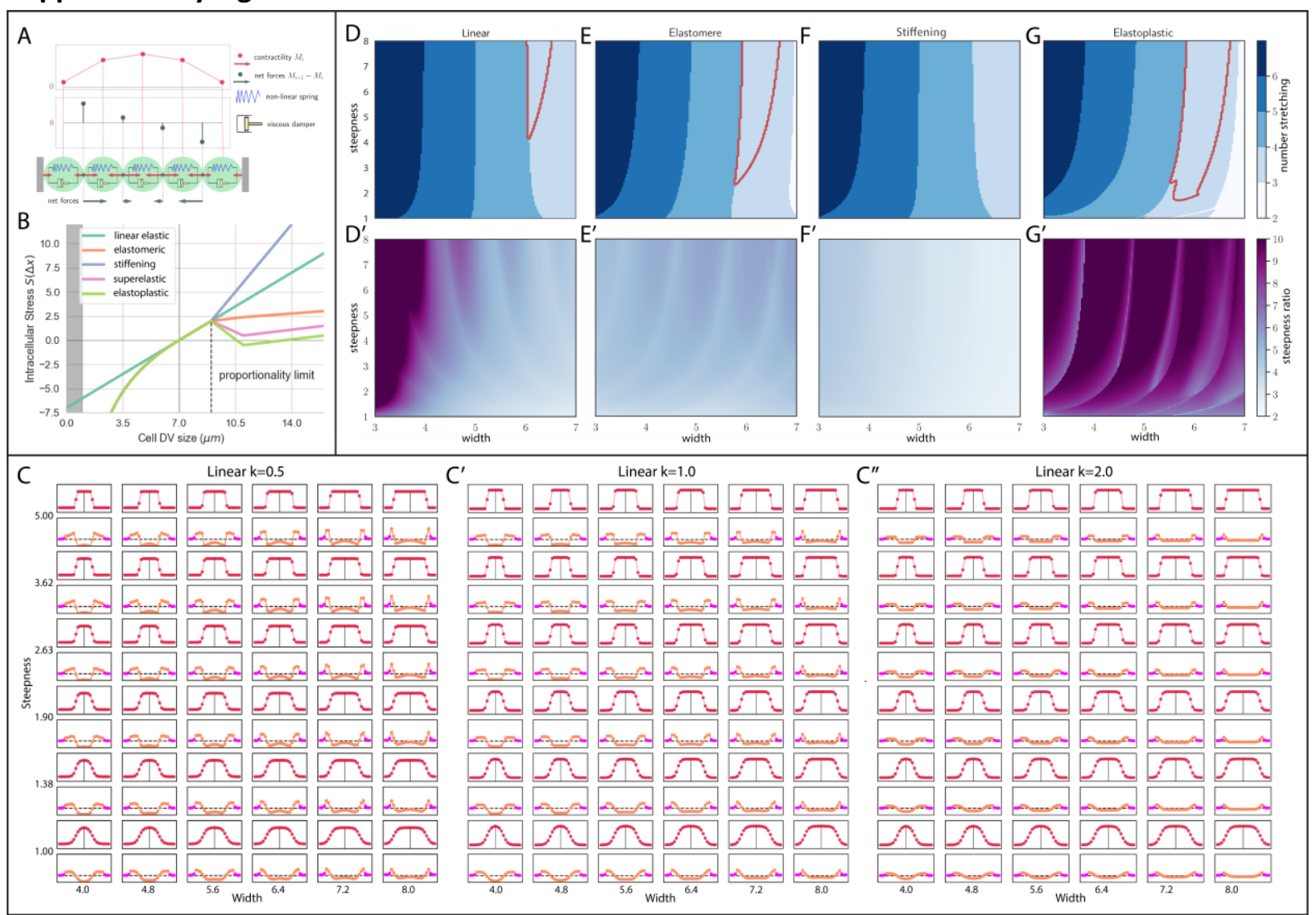

Suppl. Fig. 5. Model of a line of visco-elastic elements representing on line of cells across the mesoderm.

(A) Cells are modeled as a series of Kelvin-Voigt viscoelastic elements with viscosity $(\eta)$ and spring constant $(k)$. Cell size changes depend on the contractile forces within cells (red arrows 'pulling' on connection points) and movement of the connecting points which is determined by the differential forces (grey arrows) acting on them.

(B) Graphs for four stress-strain relationships (linear elastic, elastomeric, superelastic and elastoplastic) that are imposed on the spring constants in the model. The resting length of the cell is set to $L=7 \mu \mathrm{m}$. Deviation from the resting length causes either expansion (positive stress) or constriction (negative stress).

(C-C") Parameter scan of the myosin profile with varying steepnesses and peak widths. The myosin profiles $(M(x))$ are shown in red, and the resulting final cell sizes below in orange. The stiffer 'ectodermal' cells are marked in pink. The visco-elastic elements have linear elasticity with constant (k).

(D - F, $\left.D^{\prime}-F^{\prime}\right)$ Same marking as Fig. 20. Parameter map for myosin concentration curves with varying peak widths and steepnesses for linear elastic, elastomeric and elastoplastic materials. Blue shades: number of expanding cells. Red outline: conditions where the three right cells expand with an inverted pattern of stretching that qualitatively matches experiments. Shading in $D^{\prime}-F^{\prime}$ : ratio of the most constricted to the most expanded cell; magenta: largest size differences, light blue: minimal size differences. 
bioRxiv preprint doi: https://doi org/10.1101/2020 10.15333963; this version posted December 1, 2020. The copyright holder for this

Supplementary Figure 6
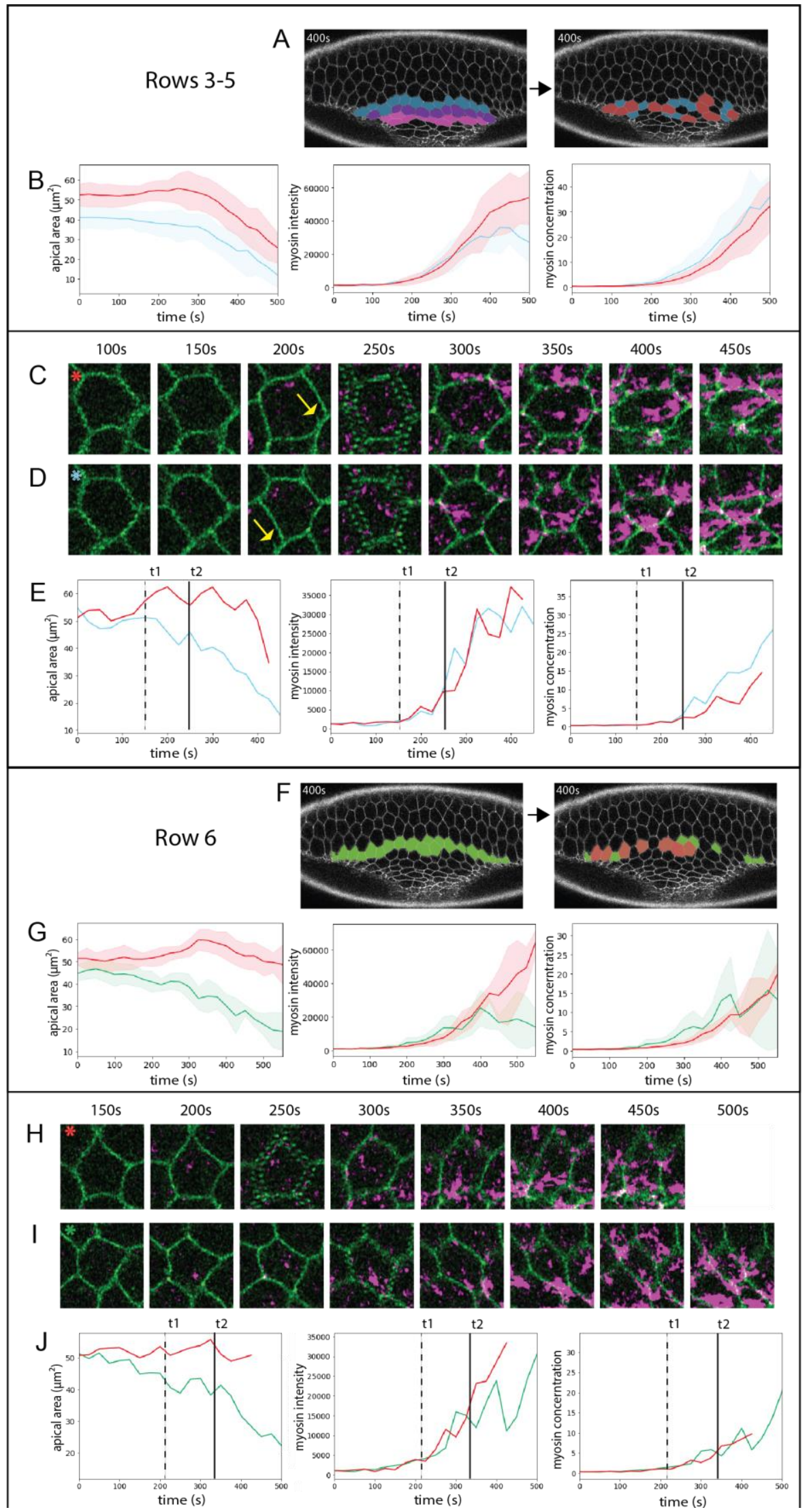

906 Suppl. Fig. 6. Myosin concentration in constricting and transiently expanding cells. 
907 Analysis of Embryo 1 expressing Spider::GFP (green) and Sqh::mCherry (magenta)(same as shown in

908 Fig. 1E). Cells in the indicated rows were sorted into bins, defining cells as 'transiently expanding'

909 (red) if they increased their apical areas by $>10 \%$ of their initial area for at least 3 consecutive time

910 points, and as contracting (blue for rows 3 to 5 , green for row 6 ) if they decreased their apical areas

911 over $10 \%$ of their initial area for at least 10 time points.

912 (A-E) Constricting rows $3-5$

913 (F-J) Transition row 6

914 (A, F) Image at $t=400$ s; left: colouring shows rows; right: colouring indicates the individual cells that

915 were analysed (red, transiently expanding, blue or green, constricting).

916 (B, G) Cell apical area, total myosin intensity and myosin concentration of constricting and transiently

917 expanding cells plotted against time, shown as mean (solid line) and standard deviation (shaded

918 area).

919 (C - E) Analysis of a transiently expanding (C) and a constricting (D) cell from the constricting rows.

920 (C, D) Snap shots of the two cells at the indicated time points. The two cells are adjacent to each

921 other: the arrow at $200 \mathrm{sec}$ points at a feature of the expanding cell that is also seen in the panel

922 below.

923 (E) Apical cell area, total myosin intensity and myosin concentration of the cells in C (red) and D

924 (blue) plotted against time. t1 (dashed line) marks the divergence of the cells in apical area, t2 (solid

925 line) the divergence in myosin concentration.

926 ( $\mathrm{H}-\mathrm{J}$ ) Analysis of a transiently expanding $(\mathrm{H})$ and a constricting $(\mathrm{I})$ cells.

$927(\mathrm{H}, \mathrm{l})$ Snap shots of the two cells at the indicated time points

928 (J) Apical cell area, total myosin intensity and myosin concentration of the cells in $\mathrm{H}$ (red) and I

929 (green) plotted against time. t1 (dashed line) marks the divergence of the cells in apical area, $\mathrm{t} 2$ (solid

930 line) marks the divergence in myosin concentration. 
bioRxiv preprint doi: https:/doi.org/10.1101/2020 10.15.333963; this version posted December 1,2020. The copyright holder for this preprint (which was not certified by peer review) is the author/funder, who has granted bioRxiv a license to display the preprint in perpetuity. It is made available under aCC-BY-NC-ND 4.0 International license.
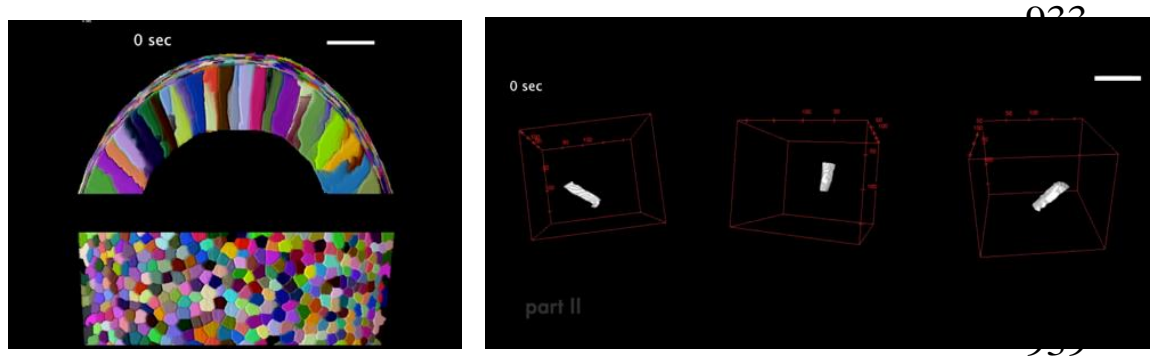

940

Suppl. video 1.

942

Part I. Cross sectional (top) and ventral (bottom) view of 3D segmented ventral half of an embryo expressing GAP43::mCherry and imaged with SPIM. Each colour marks a unique cell that is tracked in time.

945 Part II. 3D volume rendering shown over time for 3 cells: one central and two (left and right) lateral

946 mesodermal cells. The video illustrates the volume transited by the cells during ventral furrow

947 formation. The tip of the left cell moved out of the imaging volume during the period. Apical is up.

948 (scale bar $=20 \mu \mathrm{m}$ )

949

950

951

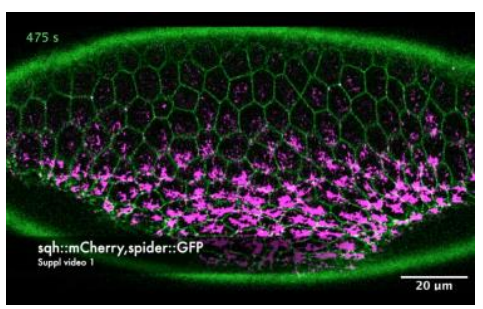

Suppl. video 2.

954 Ventro -lateral view of 2 embryos (parts I and II) expressing shq::mCherry (magenta; myosin) and

955 Spider::GFP (green; membrane) showing the dynamics of apical area and myosin during ventral

956 furrow formation and lateral cell expansion. $t=0$ in both movies is defined as 100 sec before first appearance of myosin in central mesodermal cells. 25 sec time steps. (Figs. 1 and 2)

958

959

960

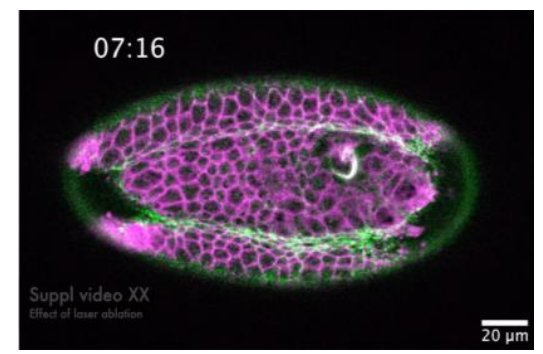

962 Suppl. video 3.

963 Ventral view of an embryo expressing GAP43mCherry (magenta; membrane), sqh::GFP (green;

964 myosin). MCP::mCherry and Snail::MS2 (not shown) were used to mark the mesoderm boundary. 
bioRxiv preprint doi: https://doi org/10.1101/2020 10.15.333963; this version posted December 1,2020. The copyright holder for this preprint (which was not certified by peer review) is the author/funder, who has granted bioRxiv a license to display the preprint in perpetuity. It is made available under aCC-BY-NC-ND 4.0 International license.

965 The embryo is illuminated repeatedly in the area marked by red ellipse in frame 1 . During the laser 966 illumination experiment, images were captured every $2 \mathrm{sec}$. The last three frames are single confocal

967 sections from a 3D stack taken at intervals of 38sec. (Fig. 3)

968

969

970

971

972

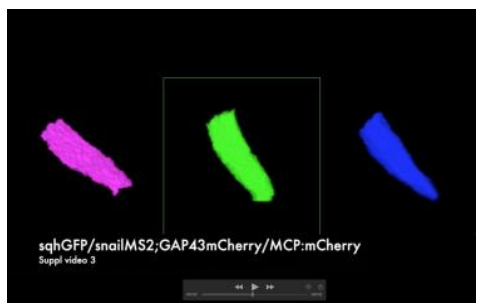

973 3D reconstructions of lateral mesodermal cells from row 7 in an embryo where apical constriction of 974 the central mesodermal cells was inhibited by laser ablation. Apical is down, basal is up. Cells 1 and 2 fail to expand, cell 3 constricts apically. See main Fig. 3E-F for location of cells in the embryo.

976

977

978

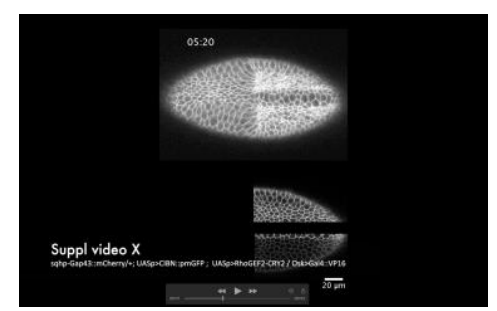

980 Suppl. video 5.

981 Ventral view of embryo expressing GAP43::mCherry (membrane, top), CIBN::pmGFP (membrane; 982 bottom) and RhoGEF2-CRY2. Myosin is ectopically activated by illuminating the area in the yellow 983 boxes in frame 1. (Fig. 4) 